\title{
Julius Büdel Und die Klima-GeomorPhologie ${ }^{1)}$
}

\author{
Armin SKowroneK, Bonn*
}

mit 3 Abb. im Text

\section{INHALT}

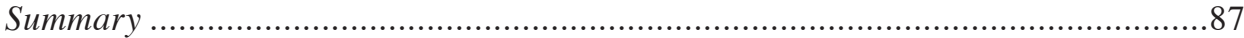

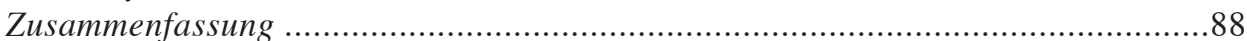

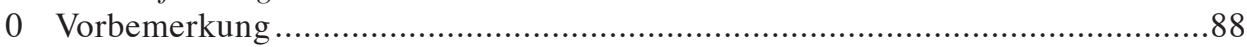

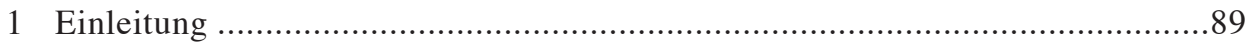

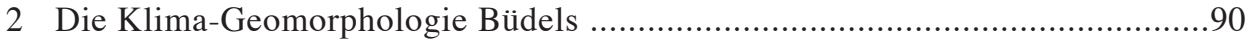

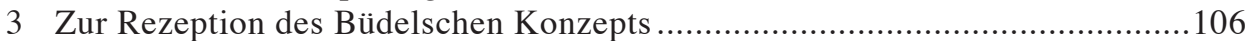

4 Stellung und Bedeutung der Büdelschen Klima-Geomorphologie ....................118

5 Literaturverzeichnis ......................................................................... 120

\section{Summary}

Julius Büdel and Climatic Geomorpholgy

The geomorphological models of peneplain and valley formation of the prominent and influential German geographer Julius BüDEL (1903-1983) are taken by a critical analysis. It demonstrates that the "double planation" in the humid tropics substantiated by weathering and soil formation processes and therefore by actual climate factors and the in the same way substantiated "ice rind effect" in the subpolar regions are not acceptable - neither pedologically nor geomorphologically. That means: these processes do not exist. They cannot explain the peneplain and valley relief outside of the recent tropics and polar regions, respectively, which was a major intent of BÜDEL. Weathering and soil formation do not act as "pacemaker" or as "motor" as BÜDEL

\footnotetext{
1) Stark erweiterte und zum Teil veränderte Fassung des gleichnamigen Vortrags auf dem 1. Forum Geomorphologie „Konzepte und Theorien der deutschen Geomorphologie und ihre Rezeption“ am 29. September 2007 in Bayreuth.

* Prof. Dr. Armin Skowronek, INRES - Bodenwissenschaften, Universität Bonn, Nußallee 13, D-53115 Bonn; E-mail: askowronek@uni-bonn.de,http://www.boden.uni-bonn.de
} 
ment, these are and remain the rivers. This was substantiated firstly by W.M. DAVIS, and developed further successfully by L.C. KING, H. LouIs and H. ROHDENBURG. Surface and channel runoff as deciding geomorphologic agents follow inherent laws - not climatic. Also a "Climatic Geomorphology" has to regard that.

\section{Zusammenfassung}

Die Modellvorstellungen des prominenten und einflussreichen deutschen Geographen Julius BüDEL (1903-1983) zur Flächen- und Talbildung werden einer kritischen Analyse unterzogen. Es zeigt sich, dass die verwitterungsgeologisch-pedologisch und damit aktual-klimatisch begründete „doppelte Einebnung “in den feuchten Tropen und der gleichermaßen begründete „Eisrindeneffekt“ in den subpolaren Breiten weder bodenkundlich noch geomorphologisch haltbar sind, d.h. diese Prozesse existieren nicht. Sie können daher auch nicht das Flächen- und Tälerrelief außerhalb der rezenten Tropen bzw. Polargebiete erklären, was ein Hauptanliegen von BüDEL war. Verwitterung und Bodenbildung fungieren nicht als „Schrittmacher" oder als „Motor “ der Abtragung wie BÜDEL meinte, das sind und bleiben die Flüsse, wie es erstmals W.M. DAVIS begründete, und wie es L.C. KING, H. LOUIS und H. ROHDENBURG erfolgreich weiterentwickelten. Oberflächen- und Gerinneabfluss als entscheidende geomorphologische Agentien gehorchen hydraulischen Gesetzmäßigkeiten - nicht klimatischen. Auch eine „Klima-Geomorphologie“ hat dies zu berücksichtigen.

\section{Vorbemerkung}

Es ist nicht üblich, über ein Vierteljahrhundert nach dem Tod eines hochangesehenen und hochgeehrten Wissenschafters noch einmal dessen Werk kritisch zu beleuchten, zumal dies schon in mehreren Würdigungen und Nachrufen erfolgt zu sein scheint. Zwei Gründe haben mich zu einer umfassenden Auseinandersetzung mit den geomorphologischen Kernaussagen von Julius BüDEL bewogen.

1. Ein Forum, das sich mit den „Konzepten und Theorien der deutschen Geomorphologie und ihrer Rezeption“ beschäftigt, bedarf auch einer Kritik der Modellvorstellungen aus damaliger und heutiger Sicht, um eine geeignete Grundlage für weiterführende Ideen zu schaffen.

2. Das betrifft besonders BüDEL, weil dieser mit seiner „Klima-Geomorphologie“ einen sehr eigenwilligen Weg einschlug, seine klimatisch begründeten Theorien der Flächenbildung und der Talbildung aber nicht stimmig und (natur)wissenschaftlich nicht nachvollziehbar sind. Ich betrachte es als meine Pflicht, dezidiert darauf hinzuweisen. 


\section{Einleitung}

Das kontinentale Abtragungsrelief der Erde kann auch als das Resultat des Aufeinandertreffens endogener und exogener Kräfte betrachtet werden. Die entstandenen Oberflächenformen zeichnen zwar lokal und regional vielfach noch die Architektur der Lithosphäre (Tektonik) und die Struktur der Gesteine nach: es bilden sich tektonisch/vulkanisch bedingte und struktur- bzw. gesteinsabhängige Formen. Der Großteil der Formen verdankt seine Entstehung jedoch den Einwirkungen der Atmosphäre, wobei der Oberflächenabfluss weithin Täler, Hänge und Flächen geschaffen hat (vgl. A. PENCK 1905).

Die mit den Oberflächenformen befasste Wissenschaftsdisziplin Geomorphologie hatte unter dem Einfluss des amerikanischen Geologen und Harvard-Professors William Morris DAvis (1850-1934; 1908/09 Austauschprofessur mit Albrecht PENCK/ Berlin) das fluviale Abtragungsrelief lang als reine Funktion der Zeit angesehen (DAvis 1899): Stadium der Flusserosion mit Talbildung (youth), dann freie Flussmäander und zurückgewichene, zerschnittene Hänge (maturity) und schließlich Bildung einer Fastebene oder Peneplain bzw. eines Endrumpfes (old age). Auch strukturbezogene Konzepte wirkten noch lange nach.

Es war der deutsche Geograph Julius BüDEL (1903-1983), der nach den Worten seiner Schüler (W.-D. Blümel, H. Gossmann, H. Mensching, O. Seuffert, H. Späth, G. StÄBlein, A. WirthmanN) diese Wissenschaft aus den engen Fesseln befreit und in eine neue Richtung, die Klima-Geomorphologie, gelenkt hat (WIRTHMANn et al. 1983, S. 344). Und wie sein Berliner Weggefährte und Freund Herbert LouIs (1900-1985) in einem Nachruf ausführte, hatte BüDEL schon sehr früh aufgrund von Untersuchungen im westlichen Erzgebirge (1935) Ideen zu einer Tropen- und zu einer PeriglazialGeomorphologie entwickelt, bevor er diese zu einem Gedankengebäude ausbaute (Louis 1983, S. 146).

BüDELs Werk wurde zu seinen Lebzeiten und nach seinem Tod (28. August 1983) gewürdigt. Eine Bibliographie seiner Arbeiten (Nr. 1-117) findet sich bei Troll (1973, S. 250-253) und fortführend (Nr. 118-139) bei Mensching (1984, S. 166). Hagedorn (1984) und STÄBLEIN (1984a) beschrieben kurz Lebensweg und Lebenswerk.

Julius BÜDEL forderte mit seinen wissenschaftlichen Ideen in der Vergangenheit immer wieder zum Widerspruch heraus. Aber auch eine heutige Beschäftigung mit seiner Klima-Geomorphologie reizt dazu. Der Autor ergreift deshalb die Gelegenheit des 1. Forums Geomorphologie „Konzepte und Theorien der deutschen Geomorphologie und ihre Rezeption“, die klimageomorphologischen Kernaussagen BüDELs noch einmal kritisch zu durchleuchten und in einen (weitestgehend synchronen) wissenschaftlichen Kontext zu stellen. Eine Auseinandersetzung mit BüDELs Modellvorstellung zur Flächenbildung erfolgte bereits in der Habilitationsschrift (SKOWRONEK 1987, S. 130-134). 


\section{Die Klima-Geomorphologie Büdels}

Mit der - 1982 als „Climatic Geomorphology“ ins Englische übersetzten - “Klima-Geomorphologie" verband BüDEL (1977) zwei Aufgaben: 1. die Ausweisung rezenter Formungsmechanismen bei der fluvialen Abtragung in Tiefländern und mittelhohen Lagen („Klimatische Geomorphologie“ = „Climatic Geomorphology“) und 2. die Ausweisung von Reliefgenerationen, welche durch Klimawandel in der reliefgeschichtlichen Vergangenheit (Oberkreide und Känozoikum) entstanden waren („Klimagenetische Geomorphologie“ = „Climatogenetic Geomorphology“). Letztlich ließen sich die Formen des fluvialen Abtragungsreliefs auf zwei grundverschiedene Prozesse zurückführen: Talbildung oder Flächenbildung.

\subsection{Rezente Formungsmechanismen}

Einen unvereinbaren Gegensatz von klimabedingter Talbildung auf der einen Seite und von klimabedingter Flächenbildung auf der anderen Seite machte BüDEL nach seiner ersten Indien-Reise 1964 auch in einer Graphik deutlich (1966, Abb. 5; vgl. hier Abb. 1).

Die Ursache für diese grundsätzlich verschiedenen Formbildungs-Prinzipien liege im unterschiedlichen Verhalten des Wassers im Boden: in rezenten Periglazialgebieten sorge das Bodeneis des Dauerfrostbodens für eine rasche Aufbereitung des Gesteins, welches dann während der Auftauperiode unter der Talsohle wesentlich schneller abtransportiert werde als auf den Hängen. Auf aktiven tropischen Rumpfflächen dagegen führe die nachhaltige Durchfeuchtung der tiefgründigen Rotlehmprofile zu

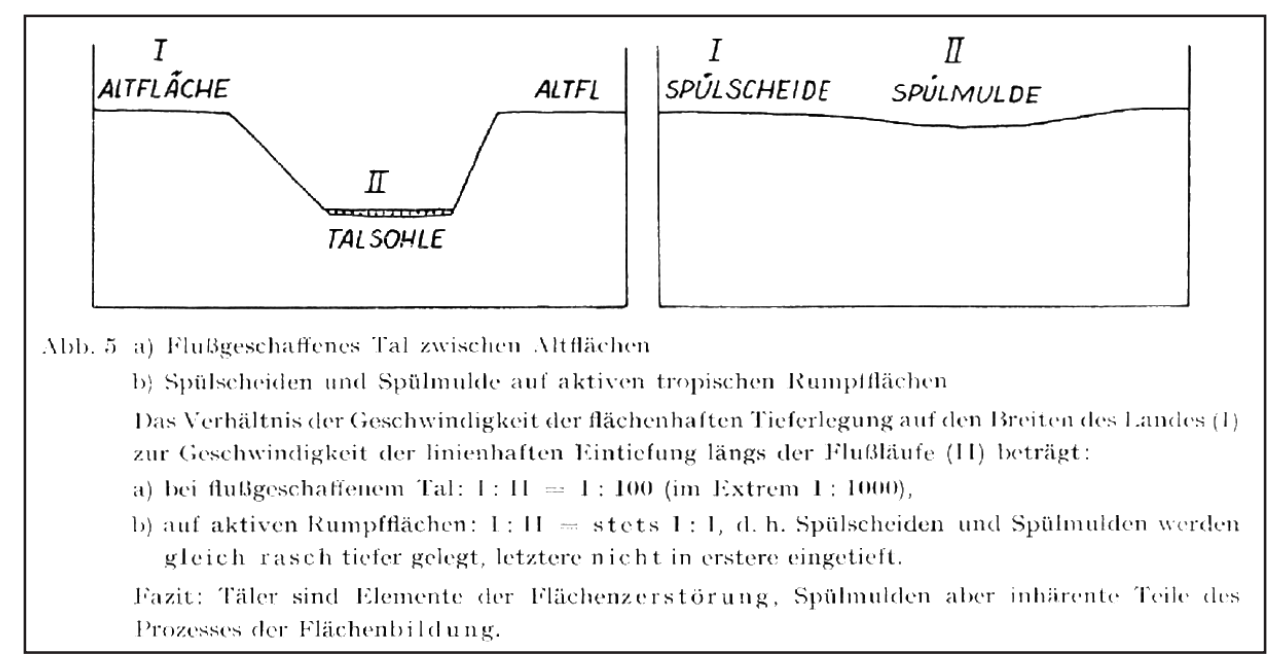

Abb. 1: Büdels Modellvorstellung der Unvereinbarkeit von Tal- und Flächenbildung (unverändert aus 1966, S. 117). 
permanenter Tiefenverwitterung an der Basis (,Verwitterungs-Basisfläche“), und an der Oberfläche („Spül-Oberfläche“) zur Bereitstellung von Feinmaterial, das von den Gerinnen dann nur passiv abtransportiert werden müsse. Spülmulden seien keine Täler, sondern völlig in das übergeordnete Wirkungsgefüge der Flächenbildung eingegliedert. Daher würden Spülscheiden und Spülmulden auch gleich rasch tiefergelegt.

Diese Modellvorstellung von Flächen- und Talbildung begründete BüDEL mit der sogenannten „Doppelten Einebnung“ (1957) und mit dem sogenannten „EisrindenEffekt“(1969).

\subsubsection{Exzessive Flächenbildung durch doppelte Einebnung in den feuchten Tropen}

Auf dem 31. Deutschen Geographentag 1957 in Würzburg stellte BüDEL im Schwerpunkt II "Die Flächenbildung in den feuchten Tropen” (sechs Vorträge) eindrucksvoll sein Konzept der „Doppelten Einebnungsflächen“ und deren Bedeutung für die klimagenetische Interpretation von Abtragungsflächen vor (1958, S. 89-109). Noch im gleichen Jahr erschien gesondert die theoretische Formulierung dieser Modellvorstellung (BüDEL 1957).

Ausgehend von einem ungleichen „Stärkeverhältnis“ zwischen flächenhafter und linienhafter Abtragung postulierte BüDEL (1957) zwei räumlich und funktional getrennte Flächen, nämlich die sog. „Spül-Oberfläche“ (auch „Material-Transportfläche“ mit „Durchgangsaufschüttung“) und die sog. „Verwitterungs-Basisfläche“, die „,eigentliche Abtragungsfläche“, da diese der verwitterungsbedingte „Schrittmacher“ der flächenhaften Tieferlegung der Erdkruste sei. Zwischen „Oberer“ und „Unterer Einebnungsfläche“ erfolge so eine „Arbeitsteilung“. Das im Durchschnitt 30 m mächtige, ,ausgereifte Bodenprofil“ “ dazwischen diene der Aufbereitung hochbeweglichen Feinmaterials (Ton und Feinsand) und als „Isolierpolster“ zwischen diesen Flächen. Daher könne der Oberflächenabfluss - als verwilderter Fluss mit „Lateralerosion“ im Sinne von WisSMANN (BüDEL 1957, S. 210), als „,allgemeine Flächenspülung“ oder als „Gullyspülung“ - die „Untere Einebnungsfläche“ auch nicht erreichen. Die Flächenbildung grenze an die höhere Umgebung mit sog. „Spülpedimenten“, die aber im Gegensatz zu den Pedimenten arider Gebiete ,hier nicht durch Lateralerosion, sondern durch den geschilderten Flächenspülungsvorgang, d.h. durch eine Kombination mechanischer und chemischer Vorgänge“ erzeugt werde (BüDEL 1957, S. 211).

Die Theorie der „Doppelten Einebnungsflächen“, welche WIRTHMANN - Doktorand und Habilitand von BüDEL - 1987 (S. 176; siehe auch 2000, S. 255) als „bahnbrechend" einstufte, enthielt wesentliche Elemente dessen, was der deutsche Geograph CREDNER zur Erklärung von Abtragungsebenheiten in Monsun-Asien herangezogen hatte (CREDNER 1932). Schon dieser ging von einem ungleichen „Kräfteverhältnis“ zwischen „linearer Erosion“ und „flächenhafter Denudation“ aus. Besonders seine Tafel I „Erosive Tieferlegung einer intramontanen Ebene und Entstehung von Fußhügeln“ ist fast identisch mit der späteren Abbildung 5 „Doppelte Einebnungsflächen und Rumpftreppenbildung“ BüDELs (1957, S. 209). Nur die Substrate unterscheiden sich: bei CREDNER waren es „Flusssedimente“ über einer „Verwitterungsdecke“, bei BüDEL war es die „Rotlehm- und Kaolinverwitterung“. Darüber hinaus könne nach 
Credner (1932, S. 17) eine unter den 6 bis 20 m mächtigen Sedimenten ,,an der Arbeit“ befindliche Intensivverwitterung das Gesteinsmaterial so beweglich machen, dass die hin und her pendelnden Flüsse in der Lage seien, ,,das gesamte Niveau der Ebene auf diese neue Basis herabzudenudieren“. BüDEL hat diesen Aufsatz CREDNERs erst viel später und nur kurz diskutiert, seine wahre geomorphologische Aussage aber nicht adäquat behandelt (vgl. 1977, S. 126; 1982, S. 163).

Eine erste Reaktion auf die „Doppelten Einebnungsflächen“ kam von TRICART (1958, S. 29). Der französische Geomorphologe folgerte aus der Analyse der BüDELschen Arbeit: „Cette vue ingénieuse ne correspond malheuresement pas aux faits“, weil derartige Einebnungsflächen sich aktuell nur in den Savannen bilden und erhalten könnten, in denen die „décomposition“ gering sei. Diejenigen unter Wald seien quartären Alters und stammten aus ariden Phasen.

Wahrscheinlich durch die Arbeiten seines Berliner Habilitations-Mentors Norbert KREBS (1876-1947) angeregt, bereiste BüDEL erstmals im März 1964 (2. Indien-Reise Jan./Feb. 1981) dessen ehemaliges Forschungsgebiet Südindien, um „den Bildungsmechanismus aktiver Rumpfflächen in der Flächenspülzone sowie deren Verhältnis zu den übrigen dort vorhandenen Relieftypen“ zu untersuchen (s. BüDEL 1965, S. 8 und Abb. 4; vgl. auch 1957, Abb. 1b). Auf der Tamilnad-Fläche sah BüDEL den „Mechanismus der doppelten Einebnungsflächen“ verifiziert. Die vorher noch diffus und widersprüchlich formulierte laterale Ausdehnung (s.o.) geschah jetzt durch den Prozess der sog. „,subkutanen Seiten-Denudation“ mit einer „Doppel-Arbeitskante SB-Akk“ (BüDEL 1965,Abb. 2). „Verstärkt“ würde jene durch das von den Inselberghängen herab rinnende Regenwasser. Als Beispiel für eine derartige „Unterschneidung“ stehe ein bis „5 m mächtiges, monogenetisches Rotlehmprofil auf einem Spülpediment“ bei Kolar (1965, Bild 2; vgl. auch 1977 und 1982, Foto 15). Ein Jahr später benannte er den Vorgang in „subkutane Rückwärts-Denudation“ um und setzte diesen - geochemisch im Kristallin nicht erklärbaren - Prozess mit der „Lösungsunterschneidung“ LEHMANNS (1953, S. 561 und Bild 8; siehe auch Wissmann 1954, S. 124) im tropischen Karst gleich (BÜDEL 1966, S. 119 und Abb. 6). Für diese Art der Seitenerosion benutzte KreBS (1929) im dinarischen Kalkgebirge den Begriff „Karstdenudation“. Aber auch in den tropischen Rumpfflächen (z.B. Südindiens) mit „Flächenspülung“ und „Spülrinnen“ gelte: „Am Fuß der Inselberge hält sich die Feuchtigkeit im Schutz der herabgefallenen Trümmer etwas länger und hier vermag die chemische Wirkung auch noch in die Trockenzeit hineinzureichen, so dass der Berg von unten her mehr angegriffen wird als von oben, der Knick an seinem Fuß also immer deutlicher wird“, oder: „Ohne wesentliche Erosionswirkung, aber unter dem Einfluss der in den Gesteinsfugen unter der Oberfläche wirksamen Feuchtigkeit vollzieht sich die Untergrabung der Berge und die Gestaltung der Ebenen“ (KREBS 1942, S. 15-16). Im Übrigen postulierte KreBS mehrfach eine „klimatische Differenzierung“ der Geomorphogenese (z.B. 1933, S. 721).

Eine sehr fundierte - und mutige - Kritik seiner Indienarbeit (1965) erfuhr BüDEL durch den Louis-Doktoranden R. Meyer (1966). Dabei wies dieser systematisch auf Unklarheiten, auf Unstimmigkeiten und auf Vorstellungen hin, die nicht zutreffen könnten. In Kürze sind dies: 
1. Die Unterscheidung von „Spülmulden“, ,Spültälern“ und Tälern (nach herkömmlicher Auffassung) laufe lediglich auf „quantitative Formunterschiede“ der begleitenden Hänge hinaus.

2. Der Grund für die angebliche „Unfähigkeit der Flüsse zur Tiefenerosion“ sei nicht das Fehlen von „Erosionswaffen“ (Geschiebe, Bodenfracht), sondern das Verhalten der Erosionsbasis bzw. der Zustand der bodenschützenden Vegetation. Im ersten Fall würden z.B. die Ränder von Rumpfflächen deshalb zertalt, weil sich die Erosionsbasis tiefergelegt habe, und im zweiten Fall könnten ,anthropogene Wasserrisse“ auch ohne Beteiligung von „Erosionswaffen“ entstehen, weil die natürliche Vegetation vernichtet und dadurch die Abflussintensität erhöht sei.

3. Der „Mechanismus der doppelten Einebnungsflächen“ allein erkläre keine Flächenbildung, das aufbereitete, feinkörnige (Boden-)Material könne nur dann abgeführt werden, wenn die Vegetation weit genug geöffnet sei und akzentuierte Niederschläge Abflussmenge und Abflussgeschwindigkeit erhöhten.

4. Die Ausbildung von Flachhängen vor steileren, hangparallel zurückweichenden Kristallin-Inselbergen sei von zwei Korngrößenmaxima, den Grobblöcken der „Residualhalden“ und dem grusig-sandigen Feinschutt, abhängig. Der Abfluss schaffe sich selbst diejenige Neigung am Flachhang, welche für den Transport der feineren Fraktion nötig sei. Die „,subkutane Seiten-Denudation“ sei nicht entscheidend.

BüDEL erwiderte diese Kritik nicht, versuchte aber, den Tal-Begriff zu transformieren und an seine genetische Vorstellung von „Spülmulden“ anzupassen (1969, S. 9-15; 1970a, siehe auch 1972a; vgl. z.B. mit FräNZLE 1968). LouIs selbst haben BüDELS Ideen zur tropischen Rumpfflächenbildung nie losgelassen. Sowohl in seinem Nachruf auf BüDEL als auch in seinem letzten Aufsatz ließ er aber keinen Zweifel daran, dass die Flüsse das steuernde Element der Landabtragung seien und dass darin kein grundsätzlicher Unterschied zwischen Täler- und Rumpfflächenlandschaften bestehe (Louis 1983, 1986).

Es ist geochemisch weder vorstellbar noch erklärbar, dass eine ,, autochthone Latosoldecke" einen kristallinen Inselberg - noch dazu gegen ein Gefälle von maximal $4^{\circ}$ - mittels „doppelter Rückwärts-Denudation“ unterschneiden soll (BüDEL 1970b, Fig. 11). Zwar hatte CLAYTON schon eine ähnliche Erklärung versucht (1956, Fig. 17), doch konnten RuXton \& BERry (1961, Fig. 2, 3, 7 und 8) zeigen, dass physikalische Mobilität des Regoliths, Bodenwasserregime und Hangdenudation kausal bei der Ausbildung des Hangknicks zusammenwirken - sowohl unter humiden als auch unter ariden Bedingungen. Und Boquier et al. (1977, Fig. 3 und 4) demonstrierten in hervorragender Weise die pedologische Differenzierung von Inselberg, Hangknick und Glacis/Pediment sowie deren geomorphologische Folgen.

BÜDELs Doktorand Gossmann hätte nicht „,vernunftwidrig“ rechnen müssen (1970, S. 87-90), wenn jener die richtige Vorgabe gemacht hätte. Das Spülmodell „mit nicht ausgelastetem Transportvermögen in steileren Hangabschnitten“ (GossmANN 1970, Abb. 25a) würde genau den Hang beschreiben, den BüDEL am 10. März 1964 bei Kolar/ Südindien fotografiert hatte: der Flachhang besteht nämlich nicht aus einem „monogenetischen Rotlehm“, sondern aus (pedogen leicht veränderten) Bodensedimenten, also aus den korrelaten Aufschüttungen einer Bodenabtragung am Inselberghang - d.h. aus 
einem Schwemmfächer (Sкоwronek \& MurTi 2005). Eine entsprechende Reliefform bzw. Stratifizierung ist auch schon in BüDELs Fotografie zu erkennen (1965, Bild 2; 1977 und 1982, Foto 15; siehe hier Abb. 2a).

\section{Gleichzeitigkeit von Pedogenese und Geomorphogenese?}

Im Gegensatz zu seinen Erkenntnissen in den Mittelbreiten (z.B. 1944, S. 489) ging BüDEL in den Tropen davon aus, dass die flächenhafte Abtragung hier durch die Prozesse der Bodenbildung und der Verwitterung kompensiert werde, dass also ein dynamisches Gleichgewicht zwischen zwei sehr verschiedenen Vorgängen herrsche (z.B. 1971, S. 31). Der „Mechanismus der doppelten Einebnung“ impliziert ein solches Postulat.

Das widerspräche jedoch bodenkundlicher Erkenntnis und Logik. Wie könnte man z.B. die innere Gliederung eines ca. 40 m mächtigen südindischen „High-Level“Laterits in nichtverhärtende und in indurable Horizonte erklären, wenn er während seiner Bildung unter humidem Klima ständig an der Oberfläche abgetragen worden wäre? Die differenzierenden pedochemischen Prozesse im Boden benötigten nicht nur Zeit, sie hätten sich auch gar nicht einstellen können, wenn das Bodenmaterial infolge Oberflächendenudation permanent an die oxidierende Atmosphäre exponiert worden wäre. Denkbar wäre lediglich eine Tieferlegung der Bodenoberfläche durch subterrane chemische Denudation (Trendall 1962, Fig. 3). Die heute krönende FeKruste dagegen könnte als eine pedologische Anpassung an mechanische Denudation aufgefasst werden - beides (mech. Denudation und Kruste) aber unter semiarid-ariden Klimabedingungen (vgl. SEufFert 1973).

Auf der „lateritbedeckten Fläche von Bangalore“ erkannte BRUnNER (1970, Abb. 2 und 3) an pedimentierten, jetzt in Reliefinversion befindlichen Resten mio-pliozäner Laterite, dass reliefwirksame Klimawechsel in der jüngeren geologischen Vergangenheit stattgefunden haben müssen. Auch zwei Akkumulationsterrassen, die ältere bis zu $40 \mathrm{~m}$ mächtig und einen Ochrept (Braunerde) tragend, interpretierte er als Produkte einer ariden, risszeitlichen Phase bzw. einer anthropogen ausgelösten, unter aktuellsemiaridem Klima ablaufenden Bodenerosion (Abb. 5). Verschiedene Typen von in-situ-Verwitterung veranlassten ihn zur Abtrennung von sieben Reliefgenerationen und Relieftypen (BRUNNER 1969, Fig. 1). Die auf einer Habilitationsschrift beruhende, über $4.500 \mathrm{~km}^{2}$ umfassende geomorphologische Detailkartierung beinhaltete auch die gesamte Bangalore-Fläche und Teile der angrenzenden Tamilnad-Fläche (BRUnNer 1968a, 1968). Besonders die (boden)stratigraphischen Ergebnisse ermöglichten jetzt eine differenzierte Ansprache der Substrate, in denen rezente Abtragung stattfindet.

BÜDEL ignorierte auf seiner Reise im März 1964 von Madras nach Bangalore und zurück die von Krebs (1936, Fig. 20) angegebenen Laterit-Vokommen zwischen Bangalore und Kolar - die neben den Inselbergen auffälligsten Reliefformen (BÜDEL 1965, S. 8 und Abb. 5; siehe aber S. 13 und S. 76, Anm. 39 sowie S. 16, Anm. 4). Auch die spätere, vergleichsweise wenig differenzierte geomorphologische Karte seines südindischen Arbeitsgebietes ließ die Laterite außer Acht (BüDEL 1977 und 1982, Fig. 44; siehe aber Fußnote 39). Büdel lernte BRUnner im November 1964 kennen (BüDEL 1965, S. 97 und 1966, S. 122, Fußnote 6) und listete im Literaturverzeichnis seiner Klima-Geomorphologie drei Titel von BRUNNER $(1968,1969,1970)$ auf. Bei der 
Darstellung der „randtropischen Zone exzessiver Flächenbildung“ - mit zahlreichen Verweisen auf die Tamilnad- und Bangalore-Fläche (5 Figuren, 8 Fotos) - kommt der Name BRunNER jedoch nicht vor (BüDEL 1977, S. 92-144; 1982, S. 120-185). An anderer Stelle brachte er BRUNNER (1968) dagegen in einen - für den Leser nicht nachvollziehbaren - Zusammenhang mit der „doppelten Einebnung“ (BüDEL 1981a, S. 56).

Es war eines der großen Verdienste des deutschen Geologen Kraus, streng zwischen Sedimenten unterschiedlicher Provenienz auf der einen Seite und Verwitterungsbildungen in situ (= Böden) auf der anderen Seite unterschieden zu haben. Diese geologisch-bodenkundliche Differenzierung ermögliche „u n m i t t e 1 b a r“ die Trennung verschiedenaltriger und die Vereinigung zusammengehöriger Oberflächen sowie „m i t t e 1 b a r“ die Aufklärung des Klimas beim Sedimentationsvorgang und des Klimas bei der Bodenbildung. Letztlich sei dadurch also die Indikation eines Klimawechsels möglich (KRAus 1923). Damit wurde eine allgemeingültige bodenkundliche Gesetzmäßigkeit formuliert, die der Geomorphologie große Dienste leisten könne.

Die Unvereinbarkeit einer gleichzeitigen Bodenbildung und Abtragung kam auch in der geologisch-geochemischen Theorie der „Biostasie et Rhexistasie“ von ERHART (1956) deutlich zum Ausdruck. Wie aus dem Begriffspaar ersichtlich, entspräche Biostasie einem biologischen Gleichgewicht - auf stabilen Landoberflächen mit Vegetationsbedeckung und mit Bodenbildung. Rhexistasie dagegen sei identisch mit einem biologischen Ungleichgewicht - auf instabilen Landoberflächen mit verschiedenen Typen von Sedimentumlagerung.

Aus der Existenz begrabener (fossiler) Böden entwickelte ButLER (1959) die Idee des sogenannten ,soil cycle“. Dieser bestehe aus dem Alternieren einer Instabilitätsphase (= Zerstörung oder Überdeckung älterer Bodenoberflächen) mit einer Stabilitätsphase (= fortschreitende Bodenentwicklung auf neuen Oberflächen). Der „soil cycle“ solle eine Zeiteinheit („K cycle“) darstellen, Serien von „K cycles“ ergäben ein chronologisches System. Um die „land surfaces“, „surfaces“ und „erosion surfaces“ der Geomorphologen auch bodenkundlich zu manifestieren, definierte er pedologisch involvierte Landoberflächen als sog. „,groundsurfaces“ (S. 8-10). Klimatisch bedingte Wechsel von Stabilität und Instabilität einer Region könnten an deren Böden festgemacht werden (Fig. 3). ButLER wies auch darauf hin, dass die „man-induced erosion“ vielfach eine (schwächere) Phase der Instabilität - in einer von Natur aus stabilen Region - erzeuge (S. 16-17).

Es war der deutsche Geomorphologe und Bodenkundler Heinrich RoHDEnBurG (1937-1987), der vor bodenstratigraphischem Hintergrund ein geomorphodynamisches Modell entwickelte, welches das Alternieren von Hangabtragung und Bodenbildung mit dem Wechsel von zwei - klimatisch bedingten - landschaftsökologischen Grundzuständen beschreibt (Rohdenburg 1970a, Abb. 2). Entscheidend sei dabei die unterschiedliche Wasserwirkung: bei dichter Vegetation mit Bodenbildung (und Bodenschutz) sei der Oberflächenabfluss gering und denudativ weitestgehend unwirksam, bei Vegetationsauflichtung und gegebenenfalls Niederschlagsakzentuierung dagegen dominiere der Oberflächenabfluss mit Abtragung der zuvor gebildeten Böden. Alle Klimazonen seien im Quartär mehrfach von solchen Wechseln der „morphodynamischen Aktivität“" und der „morphodynamischen Stabilität“ betroffen gewesen, wobei das Holozän generell eine stabile Phase darstelle. 
Zusammenfassend lässt sich sagen: außer im Periglazialbereich (mit relativ langsamen, gravitativen Bodenbewegungen; siehe P.J. Williams 1966) schließen sich Bodenbildung und Abtragung prinzipiell aus. Eine horizontbildende, bestimmte physiko-chemische Bedingungen erfordernde Bodenentwicklung wäre nicht möglich, wenn die Bodenoberfläche ständig durch Oberflächenabfluss tiefergelegt würde. Eine Gleichzeitigkeit von Geomorphogenese und Pedogenese wäre lediglich in semiariden bis ariden Gebieten denkbar, wo das niederschlagsbedingte Bodenbildungspotenzial gering ist und die ,decomposition“ flach (dm) bleibt (s.o. TRICART 1958), andererseits aber auch ein Teil der Niederschläge oberflächlich abfließt und dabei flächenhaft abtragen kann.

Jeder Boden bildet zwei geomorphologisch relevante Flächen aus: die Bodenoberfläche, die unter bestimmten Bedingungen abgetragen werden kann und die Untergrenze des Solums, an der das Ausgangssubstrat aufbereitet wird bzw. wurde (pedophysikalische/pedochemische Desintegration/Dekomposition als geomorphologische „Arbeits"funktion). Je näher beide räumlich zusammenrücken, desto stärker werden ihre Interaktionen und Abhängigkeiten. Ein durchschnittlich $30 \mathrm{~m}$ mächtiges, reifes Rotlehmprofil als „Isolierpolster“ (BÜDEL s.o.) beweist das Gegenteil: hier können von der „Spül-Oberfläche“ so gut wie keine geomorphologisch wirksamen Impulse an die „Verwitterungs-Basisfläche“ ausgesendet werden, weil das „Isolierpolster“ sie abpuffert. Eine „Arbeitsteilung“ im Sinne einer Gleichzeitigkeit findet nicht statt.

Anders an Akkumulationsstandorten: hier können bodenbildende Prozesse die Sedimente gegebenenfalls in die Bodenoberfläche inkorporieren und pedogen umwandeln, wenn die Materialzufuhr nicht zu stark ist und die Böden nicht von Atmosphäre und Biosphäre isoliert werden. Auenböden im Überflutungsbereich der Flüsse oder Andosole aus (glasreichen) Pyroklastika in Vulkangebieten zählen dazu. Aber auch fossile Lößböden lassen erkennen, dass sie während ihrer Genese äolischen Materialimport erhielten. Auch in älteren Schichtgesteinen ist synsedimentäre Bodenbildung manchmal nachweisbar (z.B. BAILLY et al. 2000).

\section{Warum ektropische Ortsböden und warum tropische Arbeitsböden?}

Unter geomorphologischen Gesichtspunkten gliederte BüDEL 1977 (Fig. 9) die Pedosphäre in „Frostschutt“, in sogenannte „Ortsböden“ (Englisch: „Ectropic reliefcovering soils“), in "Trockenschutt” und erstmals in sog. „Arbeitsböden“ (Englisch: „Tropical relief-forming soils“). Letztere waren vorher (als südindische „Rotlehme“) noch „re in e Orts böd e n“ (1965, S. 17), auch irritierte die (einseitige) Definition des „Auftaubodens“: „Er stellt die Pedosphäre in Gestalt der Frostschuttdecke dar“ (BüDEL 1977, S. 49). "The literal translation of Ortsböden and Arbeitsböden would be 'in situ soils' and 'working soils' respectively” (1982, Fußnote 33 und S. 136). Abgesehen davon, dass BüDEL „Frostschutt“ und „Trockenschutt“ geomorphologisch sehr ungleich behandelte (vgl. 1977, S. 37-92 mit S. 156-196), und abgesehen davon, dass in Zonen mit „Frostschutt“ und „Trockenschutt“ echte Böden flächenmäßig überwiegen (z.B . Tedrow 1977 und Dregne 1976 im Gegensatz zu Büdel 1970, S. 3; siehe später auch EBERLE \& BlÜMEL 1994), fällt auf, dass sowohl „Ortsböden“ als auch „Arbeitsböden“ unter einer mehr oder weniger dichten, d.h. bodenschützenden Vegetation dargestellt wurden (Fig. 9). Erstere seien horizontiert (Fig. 6) und hätten eventuell schon ihr 
„Reifeprofil“" erreicht (1977, S. 22), letzteren fehle ein (horizontiertes) „,Reifeprofil“ (1977, S. 102), weil sie „in ihrem ganzen Profil ständig Vorgänge der Umlagerung, Verschwemmung und Tonmineralbildung zeigen“ (S. 96). Die Latosole wurden als das typische Beispiel von „tropischen Arbeitsböden“ angesehen, andere Bezeichnungen „unter Betonung bestimmter Sonderzüge“ seien: „Ferrallit“, „Fersiallit“, „Oxisol“ oder „Luvisol“, schließlich als verhärtete Formen „Laterit“" und „Plinthit“ (1977, S. 98). Die sog. „Tirse“, welche infolge Hydroturbation bzw. Peloturbation wirkliche „Arbeitsböden“ darstellen könnten, wurden zwar beschrieben, aber seltsamerweise keiner der beiden Gruppen zugeordnet, und dies, obwohl sie nach BüDEL 10-15\% der tropischen Tiefländer einnehmen (S. 98-99).

Hinsichtlich des Profilaufbaus der Latosole bezog sich Büdel (1977, S. 103; 1982, S. 133) im Wesentlichen auf den deutschen Agrikulturchemiker FINCK (1963, S. 50-54). Es erstaunt, dass er dabei nur die möglichen geologischen Schichtungsmerkmale hervorhob, die pedologischen Horizontmerkmale aber ignorierte (Humus, Struktur- und Texturunterschiede, Ausfällungen) und dann schloss: „die Grenze von „Boden“ und „Bodensediment“ ist fließend“ (S. 103). Die meisten ektropischen „Ortsböden“ sind ebenfalls geologisch geschichtet, was wegen der pleistozänen Landformung und der dabei gebildeten Substrate auch nicht verwundert. Geologische Schichtung und pedologische Horizontierung dokumentieren damit einen geomorphologisch wirksamen Klimawechsel. Das hatte BüDEL selbst einmal an einem postglazialen Podsolprofil aus periglazialen Hangsedimenten im Riesengebirge exemplarisch demonstriert (1944, Abb. 2), was dann aber in seiner ,Typischen Horizontgliederung ektropischer Ortsböden“" merkwürdigerweise keinen Niederschlag fand (siehe 1977 und 1982, Fig. 6; vgl. dazu auch Kritik von Semmel 2008, S. 98-99). In den Tropen ist nicht ,alles ganz anders", wie BüDEL (1977, S. 93) meinte, Schichtung bedeutet natürlich nicht, dass in diesen Sedimenten keine Bodenbildung stattgefunden hätte, sie modifiziert diese nur (z.B. FöLSTER \& LADEINDE 1967).

Die von BüDEL (1977, S. 98) anstelle des Latosols angegebene Bezeichnung „Oxisol“" wurde erstmals im neuen US-amerikanischen Bodenklassifikationssystem der "7 $7^{\text {th }}$ Approximation“ als „Order“ (höchste taxonomische Kategorie) eingeführt. Die "Oxisols" wurden als "mineral soils having an oxic horizon or having, within $30 \mathrm{~cm}$ off the surface, plinthite that forms a continous phase and that is not hardened" definiert und dann in fünf „Suborders“ unterteilt (Soil Survey StafF 1960, S. 103 und 238-246; siehe auch 1975, S. 74 und 323-332).

Die von BüDEL (1977, S. 98) für Latosol benutzten (und verdeutschten) Begriffe „Ferrallit“" und „Fersiallit“ gehören inhaltlich und klassifikatorisch zu dem auf Aubert $(1964,1965)$ zurückgehenden französischen Bodenklassifikationssystem (CPCS 1967). Auf dieser Grundlage wurden schon sehr früh Bodenkarten verschiedener Maßstäbe erstellt: für Gesamtafrika (7 sheets) im Maßstab 1:5.000.000 (C.C.T.A. 1964 und D‘Hoore 1964), dann z.B. für den Senegal im Maßstab 1:1.000.000 (MAignien 1965) oder den Tschad im Maßstab 1:200.000 (z.B. Pias \& Poisot 1964). Die „Sols ferrallitiques“ nehmen das (höchste) Niveau einer „Classe“ ein und werden nach der Entbasungs-Intensität des genetischen B-Horizontes weiter klassifiziert (CPCS 1967, S. 63-71). Die "Sols fersiallitiques“ bilden neben den „Sols ferrugineux tropicaux“ eine eigene „Sous-classe“ innerhalb der „Classe des sols a sesqioxides de fer“ (CPCS 
1967, S. 57-61). Alle Einheiten dieser Klasse besitzen ein A-B-C-Profil, manche Böden weisen sogar einen Tonverarmungs- und einen Tonanreicherungshorizont (Bt) auf. Die deutsche Bodensystematik verwendet seit 1982 wieder die Namen „Fersiallite“ anstelle von „Plastosolen“ (früher „Lehme“) und „Ferrallite“ anstelle von „Latosolen“ (früher „Erden“) für reliktische oder fossile Paläoböden auf Silikatgestein (ArbeITSGruppe BodENKunde 1982, S. 225-227).

BÜDEL setzte den „Rotlehm oder Latosol“ auch mit dem „Luvisol“ gleich (1977, S. 98). Der Name „Luvisols“ wurde 1974 von der FAO-UNESCO eingeführt, um Böden mit einem illuvialen Tonanreicherungshorizont (,argillic B horizon“ $=$ Bt-Horizont) zu kennzeichnen. Zu den Luvisols gehören auch die (deutschen) Parabraunerden oder die (kanadischen) Grey-Brown Podzolic soils (S. 18). Die FAO-Legende diente als Leitfaden für die Beschreibung der Kartiereinheiten auf den - zwischen 1971 und 1981 erschienenen - 18 Blättern der „Soil Map of the World 1:5.000.000“.

Der - in der deutschen Geomorphologie nicht unbekannte - Tropenbodenkundler SchmidT-Lorenz hatte 1971 eine sehr instruktive Arbeit vorgelegt, aus der die Entwicklung der bodenkundlichen Erkenntnisse in den Tropen und Subtropen deutlich wurde, und in der man eine exzellente Beschreibung der Bodennamen aus verschiedenen Taxonomien bzw. deren Korrelation(smöglichkeiten) finden konnte. Daher ist nicht zu verstehen, dass BüDEL $(1977,1982)$ einerseits Bodennamen aus verschiedenen Klassifikationen entlieh, um tropische „Arbeitsböden“ auszuweisen, andererseits den - pedologisch begründeten - Bedeutungsinhalt eben jener Namen ignorierte bzw. entstellte.

Warum deutete BüDEL $(1977,1982)$ die Pedosphäre auf so fundamental unterschiedliche Weise? Findet Tonmineralneubildung nicht auch in den „in situ soils“ statt? Warum sind die „moving soils in Spitzbergen“" (Sмітн 1956), welche er selbst (BüDEL 1960; vgl. auch SCHENK 1955) so trefflich kennzeichnete, nicht auch „Arbeitsböden“? Oder die „Tirse“ (Vertisols), deren „Beweglichkeit“ und „starkes Arbeiten“ er einmal beschrieb - mit der Fähigkeit zum „Flächengleiten“ analog der „Flächenspülung“ (BÜDEL 1954, S. 144)? Sie sind den Periglazialböden in geomorphologischer Hinsicht sehr ähnlich (Costin 1955) und erzeugen in verschiedenen Klimazonen sogar ein Mikro- bzw. Gilgai-Relief (Edelman \& Brinkmann 1962, Beinroth 1965; vgl. aber BüDEL 1977, S. 99 und Fußnote 31). Auch stellte BüDEL (1977 und 1982, Fig. 5) - wenig konsequent - den reliefbildenden Latosol auf die gleiche geomorphologische Integrationsebene wie die Parabraunerde, welche gerade keine Beziehung zur Reliefbildung besitze (vgl. auch BüDEL 1975, S. 6). Völlig abgehoben von jeder pedologischen Realität wirkte der Gedanke BüDELs, ,Arbeitsböden“ führten mehr ein „Phänomen- als ein Objekt-Dasein“, gleich einer Föhnwolke vor einem Gebirge (1977, S. 105; 1982, S. 137, Fußnote 33).

Weiterhin ist unklar, wie BüDEL - erstmals 1950 - zum Begriff „Ortsböden“ gelangte (1977, Fig. 9). Doch hatte der deutsche Bodenkundler RAmANn - Befürworter der Errichtung einer Bodengeographie innerhalb der Geographie (1918/19) - schon 1918 „Ortsböden“ als Böden definiert, die in einer klimatischen Bodenzone aufgrund besonderer, dominierender Einflüsse wie z.B. der Gesteinszusammensetzung nur örtlichen Charakter besäßen (S. 22ff.) und diese u.a. von den „Wanderböden“ („Kriechböden“, „Abschlämmmassen“) abgetrennt, welche infolge des Einflusses äußerer Kräfte Ortsveränderungen erfahren hätten. Die meisten Böden seien jedoch ortsstet und hätten 
ein Bodenprofil (S. 29ff.). Auch der deutsche Geograph Passarge verwendete den Begriff „Ortsböden“ in diesem Sinne (1930, S. 431 und 434).

Dass „die Entstehung der sogenannten „Ortsböden“ im Sinne von RAMANN (BÜDEL [1948])“ auch geomorphologische Relevanz besitze, zeigten RoHDENBURG \& MEYER (1963, S. 142-143) auf: Die durch die Struktur der Pedosphäre gesteuerte „chemische Denudation“ führe in Kalkgebieten einerseits zu Substanzverlust, andererseits durch Auflockerung und Humusakkumulation zu Substanzgewinn. Daher müsse die Geomorphologie neben der mechanischen oberflächenparallelen Abtragung auch die „innere Abtragung“ berücksichtigen.

„Ortsbodentypen“ als - neben den großen klimazonalen Bodentypen existierende - räumlich beschränkte, intrazonale Böden waren für TILl (1932/33) die Grundlage einer pedologischen Gliederung Österreichs. Lage und Klima (Mikroklima), Relief und Grundwasser, Muttergestein und Untergrund sowie die Bodenkultur bestimmten dabei die lokale Begrenzung dieser Ortsböden. Mit der Basenzufuhr zu tieferen Stellen in der Landschaft wurde sogar der Catena-Gedanke vorweggenommen (S. 169).

Wurde hier eine fundamentale bodenkundliche Erkenntnis stillschweigend von BüDEL aufgenommen und umgedeutet, um das eigene Gedankengebäude pedologisch zu begründen und abzusichern?

Fazit. Selbstverständlich sind tropische Böden horizontiert, und selbstverständlich besteht die tropische Pedosphäre sowohl aus (klima)zonalen Böden als auch aus „Ortsböden“ im Sinne RAmanns (1918) - und auch im Sinne BüDELs (1977, 1982). Hier existieren dieselben Gesetzmäßigkeiten der Bodenbildung wie in den Ektropen (Stremme 1917). Man vergleiche dazu einmal die Bodenprofile im - hervorragend ausgestatteten - Bodenatlas von Douchaufour (1976).

Die (geomorphologische) Unterscheidung der irdischen Pedosphäre in ektropische „Ortsböden“ und in tropische „Arbeitsböden“ durch BüDEL basiert auf falschen bodenkundlichen Prämissen.

BüdEL instrumentalisierte nicht nur den Boden sondern auch Walther PENCKs „Primärrumpf“ (1924) zur Verifizierung des „Abtragungsmechanismus“ der „doppelten Einebnung“" (siehe 1977, S. 205).

\subsubsection{Exzessive Talbildung durch den Eisrinden-Effekt in der subpolaren Zone}

Das wichtigste Ergebnis der drei Forschungsreisen nach Spitzbergen [Svalbard] (1959, 1960, 1967) war für BüDEL (1969, S. 36 und 26) die „Entdeckung der Eisrinde“", einer rund $50 \mathrm{~cm}$ dicken, eisdurchsetzten (bis 60\%) „obersten Lage des DauerfrostBereichs“, welche er habituell und hydrologisch (kryodynamisch) zwar nicht weiter beschrieb, welche aber im unvergletscherten Polargebiet ,als Motor der Tiefenerosion“ die „exzessive Talbildung“ bewirke (vgl. auch „Flusserosion“ als „Motor“, 1965, S. 23). „Derselbe Effekt fördert auch die Denudationsvorgänge auf den Hängen“ (BüDEL 1972, S. 290). Eine Zeichnung sollte den Mechanismus des „Eisrinden-Effekts“ - in einem nicht näher definierten Substrat Südost-Spitzbergens - deutlich machen (BüDEL 1977 und 1982, Fig. 34). BüDEL verallgemeinerte sein Konzept und sah sich durch die Untersuchungen SEmmels im zentralen West-Spitzbergen bestätigt (S. 80: Fußnote 19). 
Arno Semmel, Frankfurter Geograph, Geomorphologe und Bodenkundler sowie Teilnehmer der 3. Spitzbergen-Reise korrigierte später diese Behauptung BüDELs, indem er feststellte, dass der eisdurchsetzte Dauerfrostboden unter den Talböden zwar vorhanden sei, diese aber aus Lockersedimenten bestünden, somit also keine Anzeichen einer „exzessiven“ Talbildung vorlägen. SEmmEL wertete auch die Literatur sehr sorgfältig aus und kam zum Schluss, dass der Nachweis einer Zone exzessiver Talbildung, die durch den eisreichen oberen Teil des Dauerfrostbodens bedingt ist, noch ausstehe (1985, S. 28-31).

BüDEL betonte, dass die Eisrinde ,eine allgemeine Erscheinung“ und „ein bisher unbekanntes Phänomen“ sei. Ihr Mechanismus erkläre sogar die Entstehung des mit Sanden und Schottern wechsellagernden „sibirischen Steineises“ (1977, S. 61; 1982, S. 82-83). BüDEL erwähnte schon früher die Begriffe „Steineis“, „Bodeneis“ und „GrundEis“ (z.B. 1966, S. 107; 1969, S. 30; 1972, S. 9 und 12), ehe er seine Eisrinde auch mit dem - übergeordneten - (Sammel)Begriff „Bodeneis“ bzw. „Grundeis“ gleichsetzte (1977, S. 86-91, 298 und 303; 1982, S. 112-119, besonders Fig. 38, Foto 13 und 14).

Die Fairness gebietet es aber auch zu betonen, dass der norwegische Geologe Holmsen bereits 1914 alle damals bekannten, bis weit in die erste Hälfte des 19. Jhs. zurückreichenden Theorien über „Steineis“, „Bodeneis“ und „Grundeis“ intensiv in einem 132-seitigen, in seiner Muttersprache gehaltenen Aufsatz diskutiert hatte (HoLMSEN 1914) - u.a. auch die ,'Glaciéres' und gefrorenen Teile der Erdrinde außerhalb der Südgrenze der ewig gefrorenen Erde“ (S. 150). Zum Studium des „Bodeneises“ in Talböden (aus Lockergesteinen) und in angrenzenden Hängen (Akkumulationsterrassen) suchte er im Sommer 1912 ein in die Coles Bay (Eis-Fjord, West-Spitzbergen) mündendes Tal auf. Seine zwölfseitige deutsche Zusammenfassung begann HoLmSEN (1914a, S. 133) mit dem Satz: „Dem Bodeneis auf Spitzbergen hat man früher nur geringe Bedeutung geschenkt trotz der großen Ausdehnung, die es in den breiten Tälern Spitzbergens zu haben scheint“, und er schloss sie mit: „Gleichgültig welcher Auffassung von der Entstehungsart des Bodeneises man auch huldigt, so ist es jedenfalls in den arktischen Gegenden mit den angeführten Bedingungen eine allgemeine Erscheinung, die die Aufmerksamkeit der Geologen als ein bedeutender Faktor in der Morphologie dieser Gegenden verdient““ (S. 144).

Büdel zitierte Holmsen nicht, doch hatte НöGвом 1913/14 in einem Nachtrag ausdrücklich auf diese Arbeit hingewiesen (S. 390). LefFINGWELL, dem wir eine Definition und eine ausgezeichnete, systematische Darstellung des „Ground ice“ verdanken (1919, S. 179-243), widmete Holmsen eine achtseitige Diskussion (S. 224-231), nachdem er sich von dessen Arbeit eine englische Übersetzung besorgt hatte.

Im posthum von WiRTHMAnN (Teilnehmer aller Spitzbergen-Reisen) herausgegebenen und von STÄBlEIN (Doktorand und Habilitand von BüDEL, Teilnehmer Spitzbergen 1967) bearbeiteten, wissenschaftlichen Konzept BüDELs zur 3. Reise wurde der Terminus „Bodeneis“ sowohl für „Eisrinde“ als auch für „Eiskeile“ benutzt (BüDEL 1987, S. 49), und die „Eisrinde“ stand jetzt (wieder) für ein „sehr reiches KlufteisVorkommen “ (BÜDEl 1987, S. 41; vgl. aber Reinwarth \& STÄBlein 1972, Abb. 3). Es ist interessant zu sehen, dass BüDEL noch 1962 sehr oft von „Taber-Eis“ bzw. 1963 von „Taber-Eis-Effekt" sprach (S. 278) und diese - nach dem alaskischen Geologen TABER (siehe z.B. 1943) benannte - Bodeneisform korrekt als „Klufteis“ (1962, S. 348) bzw. 
als „eisgefüllte Fugen und Klüfte“ beschrieb (1963, S. 277). Zwischen 1963 und 1968 muss dann die „Entdeckung der Eisrinde“ erfolgt sein, eine(r) Begriffsschöpfung, die sich wie die abstrahierende Synthese der HoLmSENschen Formulierungen von 1914 liest (s.o.). Nach der erstmaligen Darstellung der „Eisrinde“ 1968 verwendete BüDEL nie mehr den - relativ häufig benutzten und wesentlich präziseren - Begriff ,Tabereis“, er setzte dieses auch nie mit jener gleich. Weise (1983, S. 31, 36-37, 40 und 60-61) und Semmel (1985, S. 20) behandelten „Taber-Eis“ und „Eisrinde“ aber gleichwertig. Als Herausgeber einer Sammlung klimageomorphologisch relevanter Arbeiten ging RATHJENS ebenfalls von einem identischen Bedeutungsinhalt der oben genannten Begriffe aus (1971a, S. 404).

Dieser terminologische Exkurs mag pedantisch oder sophistisch und damit überflüssig erscheinen, zur wissenschaftlichen Klarheit trug der abrupte, nicht begründete und unkommentierte Wechsel von „Taber-Eis“ zu „Eisrinde“ durch BüDEL nicht bei - im Gegenteil. Wollte man jetzt nämlich die diffuse „Eisrinde“ mit „Grundeis“ bzw. mit „Bodeneis“ gleichsetzen (s.o.), so würde man jene zu einem gleichwertigen (übergeordneten) Begriff erheben, weil darunter jetzt alle Bildungen von Bodeneis (Grundeis) subsumiert werden könnten. Das wäre eine unzulässige dialektische Verfälschung bzw. Verwässerung des Begriffes Bodeneis (Grundeis). Denn auch in einer jüngeren, systematisch-eindrucksvollen Zusammenstellung von MACKAY (1972) waren verschiedene ,ground ice forms“ - nach Herkunft und Bewegung des Wassers - schon zufriedenstellend definiert: „open-cavity ice“ (1), ,single-vein ice“ (2), ,,ice wedge“ (3), ,tension-crack ice“ (4), ,closed-cavity ice“ (5), ,segregated ice“ aus ,epigenetic ice“ (6) und ,aggradational ice“ (7) bestehend, ,sill ice“ (8), ,pingo ice“ (9) und „pore ice“ (10).

Angesichts so unterschiedlicher Grundeis-Formen im Boden stellt sich die Frage, was ist denn nun die „Eisrinde“? Ist sie alles, also das bekannte „Bodeneis“? Ist sie das frühere „Taber-Eis“ BüDELs? Oder ist sie etwas anderes? Und kann sie tatsächlich eine der Hangdenudation vorauseilende Tiefenerosion motivieren? Nach STÄBLEINS Bewertung von 1970 sei sie ,unter den Flüssen und in den Tälern zwar nicht die Ursache, so doch der auslösende Faktor der „exzessiven Talbildung“ (BüDEL 1948) im Polargebiet“ (S. 47). Auf Festgesteinen falle die „Eisrinde“ über weite Strecken aus, wie SPÄTH, BÜDEL-Doktorand und Teilnehmer der zweiten und dritten Spitzbergen-Reise, dann 1986 schrieb. Russel sah 1890 im Bodeneis Alaskas sogar ein Hindernis für die Taleintiefung: "The erosive power of surface water is thus reduced to a minimum" (S. 133). BüDEL hingegen konstatierte das gleiche, aber bei fehlendem Dauerfrostboden: „Das bedeutet eine Abschwächung der Tiefenerosion“ (1963: Fußnote 11). ANDERSSON charakterisierte 1906 das geomorphologische Vorfluter/Hangverhältnis in den eisfreien Polargebieten mehrfach mit dem Begriff „stone-rivers“, was gleichbedeutend wäre mit der Überlastung der fluvialen Transportkapazität infolge vorauseilender Hangdenudation.

Warum sollten die häufigsten Formen von Grundeis, nämlich Eiskeile und ihre weitflächigen Polygonmuster (siehe LACHENBRUCH 1962), bei Antauen bzw. nach Abtauen nicht bessere Angriffspunkte für Abtragung jedweder Art darstellen als die „Eisrinde“ (vgl. dazu z.B. LefFingwell 1915)? Außerhalb von Böden besitzt auch die - lithologisch kontrollierte - Frostkeil-Bildung höchstes geomorphologisches Potenzial (vgl. dazu z.B. Dege 1941). In ehemaligen Periglazialgebieten stellen Eiskeil(Frostkeil)- 
Pseudomorphosen (z.B. BüDEL 1977: Foto 4) auch wesentlich häufigere und viel sicherere Indikatoren für Permafrost dar als die von BüdEL (1977: Foto 5) bzw. SPÄTH (1986: Foto 6) unspezifisch illustrierte „Eisrinde“. So konnte RoHDENBURG 1966 mit Hilfe von Eiskeil-Pseudomorphosen in Lößprofilen die letzte Kaltzeit (Würm, Weichsel) erstmalig in sieben (bzw. zehn) Permafrost-Phasen mit ,generationsspezifischen Charakteristika" (S. 161) untergliedern, wobei die zwischengeschalteten - thermisch bedingten - Phasen des Permafrost-Abbaus (,Klimawellen 2. Ordnung“) mit den jungwürmzeitlichen „Nassböden“ sogar „Fe uchteoszillationen“ anzeigten (S. 166). Differenzierte „klima“"geomorphologische Schlussfolgerungen liegen auf der Hand (vgl. z.B. Semmel 1989). Bei aktualistischer Betrachtungsweise wären Eiskeilpseudomorphosen (als gesicherte Leitformen des Permafrostes) typisch für kalthumide Klimate mit einer Jahresmitteltemperatur von unter $-4^{\circ} \mathrm{C}$ und einer mittleren Temperatur des kältesten Monats von unter $-20^{\circ} \mathrm{C}$ (KARTE 1981, S. 63; vgl. auch Harris 1981). Und was die Geomorphogenese im „perig lazialen Klima“ LozINskis (1909, S. 14) betraf, so hatte der deutsche Geologe SALOMON - nach Erfahrungen in Spitzbergen (1910) bereits 1917 und 1929 detaillierte Vorstellungen für Deutschland und den Alpenraum entwickelt: seine Beschreibung und Interpretation der Wirkungen von Solifluktion und von in-situ-Frostmechanik (Lockerung bzw. Desintegration der Gesteine) sowie seine Erklärung der spezifischen Form und Lagerung der Lockermassen stellten einen großen Erkenntnisfortschritt dar.

Den wohl besten Einblick in die Kryostrukturen des oberen Permafrost-Bereiches bekommt man derzeit im über $100 \mathrm{~m}$ langen, vom U.S. Army Corps of Engineers „Cold Regions Research and Engineering Laboratory“ (CRREL) zwischen 1963 und 1969 errichteten „Permafrost Tunnel“ bei Fox nördlich Fairbanks in Alaska (vgl. zuletzt BRAY et al. 2006).

In Südost-Spitzbergen gibt es auffällige Hangkonkavitäten, welche der unbefangene Beobachter zwanglos als Fußflächen (Pedimente) interpretieren würde (vgl. BüDEL 1977 und 1982, besonders Foto 8 und 9). BüDEL selbst hatte 1969 (S. 34) diese Flachformen auch als „Unterhang-Pedimente“ identifiziert und eine „Analogie zu den Pedimenten semiarider Gebiete" erkannt, wobei er der Solifluktion aber eine weitaus stärkere Pedimentationswirkung zuschrieb (als dem Oberflächenabfluss in Trockengebieten). Acht Jahre später erschien es ihm jedoch „,widersinnig“ (1977, S. 77, Fußnote 17), „von dieser rein an eine Art der Talbildung geknüpften Form (die am Oberrand bis $15^{\circ}$ steil wird!) mit Bezeichnungen wie Kryoplanation, Pediplanation oder ähnlichen als einer Art Frost-Flächenbildung zu sprechen und diese der länderweiten Rumpfflächenbildung in den wechselfeuchten Tropen zur Seite zu stellen“. Der „Frostunterhang (durchlaufende Rampe)“ des dreiteiligen Frosthanges verdanke seine Entstehung (aus einer glazigenen Trogtalform) vielmehr der Gesamtrelief-Influenz von Altfläche, stark zerschnittenem Oberhang, weniger zerschnittenem Mittelhang (oft als Dreieckshang ausgebildet) sowie der exzessiven Talbildung. Der scharfe Knick am Fuß des Mittelhangs (Akv/1 bis Akv/4 in Fig. 30, 1977; vgl. hier Abb. 3 oben) und die Rückverlegung der Mittelhänge kämen dadurch zustande, dass deren Materialabfuhr auf dem Unterhang von den Schwemmfächern gestaut werde, die sich aus der Runsenspülung (zwischen den Mittelhangstücken) rekrutierten (Fig. 31; zur Hanggliederung siehe auch DE GeER 1910, Pl. 8 und 15). Sieben Jahre zuvor machte BüDEL (1970b, S. 24) noch eine „starke 
aktive Rückwitterung“ der steileren Mittelhangteile dafür verantwortlich und nannte die Entstehung des deutlichen Profilknicks den „aktiven Hangfuß-Effekt“. Diese Entwicklung verlaufe völlig autark, sie werde von der Tieferlegung des Talbodens (Vorfluter) nicht beeinflusst, sondern nur „ermöglicht“ (1970b, S. 29; vgl. jedoch wieder 1977, S. 77, Fußnote 17).

Büdel (1977 und 1982, Fußnote 15) zitierte dazu den von Gossmann (1970) „,berechneten Hangfußeffekt“. Doch hatte GossmanN den scharfen Hangknick und den Frostunterhang als „Effekt der Restbergversteilung“ mit vorherrschender Abspülung beschrieben und generell auf die Akzentuierung derartiger Konkavitäten mit zunehmender Aridität hingewiesen. Der abrupte Übergang der Dreiecksflächen (der Mittelhänge) in die „Fußflächen“ beim dreiteiligen (periglazialen) Hang sei der Formbildung in semiariden Gebieten ,analog“ (1970, S. 98-101; vgl. auch Міотке 1979, Fig. 4.2.1.2). An entsprechenden Klimabedingungen fehlt es in Spitzbergen nicht (vgl. НӧGвом 1912).

Nach geomorphologischen Untersuchungen an Schutthalden (in Steilhängen) schien die postglaziale Hangentwicklung in Spitzbergen jedoch nicht sehr intensiv gewesen zu sein (RAPP 1957), auch hätte ,die postglaziale Erosion die eiszeitlichen Landschaftsformen in Spitzbergen nur wenig verändert“ (W AHNSCHAFFe 1910, S. 653).

\subsection{Reliefgenerationen (am Beispiel Frankens)}

Obwohl BüDEL niemals von Aktualismus sprach, so ist doch unverkennbar, dass er seine doppelten Einebnungsflächen und seinen Eisrinden-Effekt als rezente Analoga zu den Vorgängen ansah, welche die tertiären (und älteren) Rumpfflächen außerhalb der heutigen Tropen und welche die pleistozän-kaltzeitlichen Täler außerhalb der „lebenden Periglazialgebiete“ schufen. Für die Flächenbildung stehe sein Vortrag auf dem Würzburger Geographentag (BüDEL 1958), und für die Talbildung ein Festvortrag vor der Bayerischen Akademie der Wissenschaften (BüDEL 1974).

Im Folgenden soll anhand der fränkischen Schichtstufenlandschaft gezeigt werden, was BÜDEL unter „Reliefgenerationen“ bzw. unter „Klimagenetischer Geomorphologie“ verstand. Franken war seit 1951 einer seiner Untersuchungsräume.

\subsubsection{Tertiäre Rumpfflächen}

Das West-Ost-Profil durch Franken nach ,hergebrachter Deutung“ (BüDEL 1977 und 1982, Fig. 65a), früher als „entstelltes W-O-Profil“ bezeichnet (1957a, Abb. 2), zeige eine - besonders unter Geologen verbreitete - Darstellung des geologischen Untergrundes und der davon getragenen Oberflächenformen. Dadurch kämen zwar die wirklich gesteinsabhängigen Schichtstufen realitätsnah zur Geltung (z.B. Zabelstein und Distelberg im Steigerwald), aber auch die Flächen zwischen den Schichtstufen (Schichtflächen, Schnittflächen, Stufenflächen, Dachflächen) ließen diese „der Theorie zuliebe als gesteinsbedingte Formen“ erscheinen (1957a, Abb. 2). Man könne entsprechend der klassischen Schichtstufen-Theorie postulieren, dass sich die Schichtstufen schon sehr lang in ihrer heutigen Position befänden, dass sie aber - als 
bereits herausmodellierte - Schichtstufen über weite Strecken zurückgewichen seien, dass sich die dabei zwischen ihnen gebildeten Flächen überwiegend an die Gesteinsstruktur angepasst hätten und dass alle Schichtstufen ein gleiches Alter besäßen (vgl. dazu z.B. SCHMitThenNer 1956).

Mit dem West-Ost-Profil nach „revidierter Deutung“ (1977 und 1982, Fig. 65b), früher als „wahres W-O-Profil“ bezeichnet (1957a, Abb. 3), brachte BüDEL demgegenüber - ähnlich wie TRICART (1951) - eine grundverschiedene geomorphogenetische Prägekraft zweier zeitlich aufeinander folgender Paläoklimate zum Ausdruck: Flächenbildung unter verwitterungsintensivem Tropenklima im Tertiär und Talbildung unter kaltzeitlichen Bedingungen im Pleistozän (siehe dazu auch 1977, S. 219-224 und 1982, S. 281-289). Diese Modellvorstellung ließe eine völlig neue Deutung der Schichtstufen zu. Bei der Eintiefung ober- und mittelpliozäner Abtragungsflächen in eine sarmato-pontische Initialfläche würden Schichtstufen dort angelegt, wo resistente Gesteinsschichten ausstreichen, welche später herauspräpariert würden. Damit seien die Schichtstufen viel jünger als bisher angenommen, und sie verharrten seit ihrer Entstehung weitgehend in ihrer (heutigen) Position. Das Schichtstufenland stelle eine Rumpftreppe aus verschieden alten Rumpfflächen dar. In einem derartigen geomorphogenetischen Zusammenhang seien die Schichtstufen lediglich „eine Art Arabeske“ (BüDEL 1957a, S. 10).

Diese Vorstellung einer initialen, riesigen sarmato-pontischen Spülfläche, gebildet unter wechselfeucht-tropischen Klimabedingungen, stieß erst Jahre später auf Kritik. So zeigte Graul (1963) anhand entsprechender Schnitte durch diese Fläche auf, dass wissenschaftlich nicht haltbare Konsequenzen bezüglich der Tektogenese Süddeutschlands entstünden. Neben - paläobotanisch begründeten - Zweifeln am postulierten Flächenbildungsklima (siehe auch Schwarzbach 1968, S. 56-57 und StÄBlein 1972) kam er zum Schluss, dass die Vorstellungen der klassischen Schichtstufentheorie zumindest für das Jungtertiär zuträfen. Und der deutsche Geologe ScHRÖDER erkannte an entsprechenden Einschlüssen in Vulkanruinen der Heldburger Gangschar, dass im Tertiär der Lias 40 km, der Dogger $20 \mathrm{~km}$ und der Malm $5 \mathrm{~km}$ weiter nach Nordwesten reichten als heute (1970, S. 30). Später fasste dieser Autor die geologischen Befunde noch einmal zusammen und resümierte: „Zeitlich und räumlich differenzierte Tektonik sind die Hauptursachen für das generelle Verteilungsmuster der Reliefentwicklung im Deckgebirge" (SCHRÖDER 1996, S. 55).

Erst 37 Jahre später unterzog WIRTHMANN - auch zum Widerspruch herausgefordert - BüDELs Vorstellungen von der klimageomorphologischen Entwicklung Frankens einer Revision (1994). Mit eindrucksvoller Argumentation machte er klar, dass die Gäufläche „als besonders ausgedehnte Landterrasse der Keuperstufe zu verstehen“ sei (S. 69). Und angesichts der zumeist relativ leicht erodierbaren Gesteine bedürfe es auch keiner tropischen „doppelten Einebnung“, zumal im gesamten Gäuland bisher keine entsprechenden Verwitterungs- und Bodenbildungen gefunden wurden. BüDELs Erfahrungen im Residualrelief des kristallinen Gondwana-Untergrundes (West-Afrika, Süd-Indien) könnten nicht in mitteleuropäische Schichtstufenlandschaften übertragen werden.

Was ist nun „Arabeske“, die Schichtstufenbildung nach hergebrachter Anschauung oder die Rumpfflächenbildung im Sinne BüDELs? 
Vor einer strikten Anwendung des aktualistischen Prinzips bei der Übertragung der tropischen Rumpfflächenbildung im Sinne BüdEls warnte später SEMmel (1993, S. 51), weil aus dem Vorkommen tropischer Bodenrelikte des Rheinischen Schiefergebirges nicht abgeleitet werden könne, dass diese während der Flächenbildung entstanden seien, und weil auch nicht feststehe, dass diese Paläosole Analoga zu den Böden der heutigen Tropen darstellten.

Was die verbreiteten Saprolit(h)e angeht, der Begriff wird seit BECKER (1895, S. 289) für ein „thoroughly decomposed, earthy, but untransported rock“ benutzt, so ist es meines Erachtens auch dringend nötig, auf den präkambrischen GondwanaSchilden gegebenenfalls präpaläozoische Verwitterungsbildungen zu berücksichtigen, die genetisch aber nichts mit den darauf entwickelten jüngeren Böden zu tun haben (müssen). Stammen die Saprolit(h)e gar aus dem Archaikum, dann würde das Prinzip des Aktualismus völlig versagen, weil die Atmosphäre damals reduzierend war. Präkambrische Verwitterung ist stellenweise im heutigen Relief wirksam, so z.B. in der zentralen Sahara (Skowronek 1987, S. 143-145) oder in Südnamibia (Stengel 2002). Und der flächenbildende Prozess im Präkambrium scheint die Pedimentation gewesen zu sein (G.E. WiLliams 1969). Relief-Exhumierungen müssten ebenfalls berücksichtigt werden (z.B. AmBrose 1964).

In Mitteleuropa reicht die „Geomorphologische Ära“ BüDELs (1977, Fig. 1) wahrscheinlich weit über die Oberkreide hinaus und umfasst eine Gesamtdauer von 165 Mio. Jahren (FeliX-Henningsen 1990, S. 14; vgl. auch Fliegel 1913).

\subsubsection{Quartäres Maintal}

Nach STÄBlein bestehe BüDEls entscheidender Fortschritt gegenüber den Düsseldorfer Vorträgen (siehe THORBECKe 1927) darin, „dass er die Bodenbildungen und ihre klimatische Differenzierung als Indiz und Voraussetzung für das unterschiedliche Verhältnis von Denudation und Erosion erkannt hat" (1984, S. 140).

Doch während BüDEL „Rotlehme“ für die Abtragung zu oben genannten Rumpfflächen verantwortlich machte und auch das Vorkommen auf der oberpliozänen „Hauptgäufläche“ am Bocksberg (290 m) bei Marktheidenfeld einbezog (1957a, S. 14 und 28-29), nannte er in Foto 4 seiner Klima-Geomorphologie nicht die Farbe des „Lehms“ in einem prä-eemzeitlichen Eiskeil auf der Riss-Terrasse des Mains bei Karlstadt, die aber nach seinen Angaben eine Seite zuvor „rot“" war (BüDEL 1977 und 1982, Foto 4 bzw. S. 63 und 85; siehe aber noch 1962, S. 375, Diskussionsbemerkung zu Mensching). Sein Mitarbeiter Körber hatte 1962 darauf hingewiesen, dass auch unter der altpleistozänen Aufschüttung, auf der Sohle eines (tektonisch angelegten) Maintales, „mehrere m mächtige rote Verwitterungslehme“ gefunden wurden (S. 29). Und KRAUS, den BÜDEL später einmal wegen einer paläopedologischen Unstimmigkeit heftig attackierte (1962a; zu literarischen Auseinandersetzungen siehe auch 1936), hatte bereits 1922 auf rote Holozänböden in Süddeutschland aufmerksam gemacht. Eine undifferenzierte Bewertung der Rotfärbung ,als ein generelles warmklimatisches“ bzw. ,als paläogenetisches Indiz für den betreffenden Boden“ sei jedoch nicht zulässig (B. Meyer 1979, S. 705). 
Hinsichtlich der geomorphologischen Konsequenz einer nichtkaltzeitlichen großen Taleintiefung stellte STÄBLEIN (1984, S. 146, siehe auch 1987) dann die Frage: „Was ist der Sonderfall und was der Normalfall?" Man könnte weiter fragen: Wie viele Ausnahmen verträgt die Regel, um noch Regel zu sein? Schließlich: Was ist die Regel?

BÜDEL, der auch in mündlichen Diskussionen gern zum Sonderfall erklärte, was sich nicht mit seinen Modellvorstellungen vereinbaren ließ, gliederte das Pleistozän unter geomorphogenetischen Gesichtspunkten in ein „Früh-Pleistozän“ (Dauer rund 1,5 Mio. Jahre) und ein ca. 0,8 bis 1 Mio. Jahre langes „Voll-Pleistozän“ (1978). Ersteres zeichne sich dadurch aus, dass die ältere (exzessive) Flächenbildung „nicht mehr“ und die jüngere exzessive Talbildung „noch nicht“ in Kraft gewesen sei. In Mitteleuropa stellten die „Breitterrassen“ ein verbreitetes Reliefrelikt des Früh-Pleistozän dar (S. 54). Deren „Geschiebe-Decken“ dürften „in murartigen Massenströmen mit weiten Lateralausschlägen während trockener Phasen“ transportiert worden sein. Die Begriffe Pediment oder Glacis wollte BüDEL aber weder für Form noch für Prozess verwenden (S. 55f.).

Übertragen auf das mittlere Maintal würde dies Folgendes bedeuten. Die von KÖRBER (1962, S. 49-69) beschriebenen „Plateauterrassen“, bestehend aus zwei „Übergangsterrassen“ (OÜT, UÜT) und drei „Hauptterrassen“ (OHT, MHT, UHT), zählten zu den frühpleistozänen Breitterrassen BüDEls, die Obere und Untere Mittel- bzw. Niederterrasse (OMT, UMT, ONT, UNT) dagegen stellten die vollpleistozänen, periglazialen Terrassen dar. Da diese aber in die mächtigen Lockersedimente der altpleistozänen Talaufschüttung eingesenkt sind (KöRBER 1962, Abb. 1 und 2), stellt sich - wie in Spitzbergen auch - einmal neu die Frage: wie soll man auf geomorphologischem Weg erkennen, dass es sich hier um „exzessiv eingetiefte Täler“ handelt (BüDEL 1977, Fig. 62; siehe auch 1963, S. 274-275)? Eine Kaltzeit war bisher - klimageomorphologisch - mit einer früh- bis hochglazialen Akkumulationsperiode und einer spätglazialen Einschneidungsphase zufriedenstellend charakterisiert (z.B. MensChING 1951).

\section{Zur Rezeption des Büdelschen Konzepts}

BüDELs entscheidende Aussage war, dass die Reliefbildung auf exogenen Prozessen basiere, ,deren qualitativ und quantitativ unterschiedliche Wirkungen sich streng gesetzmäßig mit dem Klima ändern“ (1980, S. 1). „Die Hauptprägestöcke holozäner Reliefbildung“ seien dabei „die subpolare Zone exzessiver Talbildung (einschließlich der Tundren und der Taiga-Talbildungszone) und die Zone exzessiver Flächenbildung in den wechselfeuchten Tropen (einschließlich der partiellen Flächenbildungszone in den immerfeuchten Tropen)“, so BüDEL 1977 (S. 91). Danach müsste man die verbleibenden sieben (gletscherfreien) „Klima-morphologischen Zonen der Gegenwart“ praktisch als mehr oder weniger stark veränderte Derivate des „Eisrinden-Effekts“ bzw. der „doppelten Einebnung“ auffassen (vgl. BüdEL 1977 und 1982, Fig. 13; siehe auch Kritik von Mensching 1984, S. 163-164).

Diese klimageomorphologischen bzw. klimagenetisch-geomorphologischen Kernaussagen allein sollen Gegenstand der folgenden Bewertung sein. 


\subsection{Rezeption in Deutschland}

Sieht man einmal von schon behandelten Kritiken (s.o.) und von den laudationes anlässlich BüDELs 60. und 70. Geburtstag (LEHMANN 1964, Troll 1973) sowie von den Nachrufen ab, so kann man die Diskussion auf die Aussagen derjenigen deutschen Forscher und Forscherinnen konzentrieren, welche ebenfalls die Reliefbildung in Periglazialgebieten und in den Tropen untersuchten.

Im - der „Subpolaren Zone exzessiver Talbildung“ BüDELs zugehörigen - WestSpitzbergen stellten BiBus et al. (1976) fest, dass die Talböden aus Akkumulationen (z.T. mit pedogenen Ah-Horizonten) bestehen, und dass die sommerlichen Schmelzwässer nicht in der Lage seien, diese Lockermaterialien auszuräumen. Der „EisrindenEffekt" wirkte sich hier nicht aus, was aber bei anderem Ausgangsrelief nicht ganz ausgeschlossen werden könne. Die Autoren plädierten danach für eine größtenteils kaltzeitliche Tiefenerosion in den deutschen Mittelgebirgen (S. 41).

Auch STÄBLEIN (1977) relativierte in Westgrönland die Exzessivität der BüdELschen Talbildung, indem er dort die Wirkung des „Eisrinden-Effekts“ ausschloss und die intensive Hangformung hervorhob. Klimageomorphologisch könne man von einer „polaren Zone intensiver Frosthangbildung mit retardierter Talbildung“ sprechen (S. 181). Und WeISE - ebenfalls Doktorand und Habilitand von BüDEL sowie Teilnehmer der dritten Spitzbergen-Reise - kam zum Schluss, „daß im Periglazialgebiet die Abtragung auf Flächenbildung hinausläuft“" (1983, S. 130). Nach Sрётн (1986, S. 3) war „die Bedeutung der Eisrinde für die periglaziale Hangabtragung größer als für die Tiefenerosion“. Und während WIRTHMANN (1976) im unvergletscherten Polargebiet noch von einer tertiärzeitlichen Flächenbildung unter nicht bestimmbaren Klimaten, aber von einer pleistozänen Talbildung im Sinne BüDELs ausging, sah PRIESNITZ (1988) alle Reliefteile in den Prozess der periglazialen Flächenbildung involviert (siehe dazu auch ANDERSSON 1906).

Die Beteiligung einer exzessiven Talbildung mittels Eisrinden-Effekts an der Bildung von Tal(terrassen)generationen unserer Mittelgebirge ist nicht nur mangels überzeugenden Nachweises im ,lebenden Periglazialgebiet“ nicht zwingend, sondern auch weil eustatische Meeresspiegelschwankungen den gleichen Effekt zu bewirken schienen (vgl. RoHDENBURG 1968).

Jüngere Forschungen auf Spitzbergen berücksichtigten die BüDELschen Ideen zur periglazialen Reliefbildung nicht mehr (vgl. BLÜMEL 1993, 1994).

Zwischenfazit. Das schon 55 Jahre zuvor von Holmsen (1914, 1914a) diskutierte, von BÜDEL 1969 zur talbildenden „Eisrinde“ transformierte „Bodeneis (Grundeis, sibirisches Steineis)“ kann nach einschlägigen Befunden in Lockersedimenten polarer Talböden nicht die Ursache für fluviale Einschneidung in Festgesteinen sein, was angesichts des exzessiven Charakters der Eisrinde zu erwarten wäre. Auch die entsprechende Graphik vom „Eisrinden-Effekt“ kann darüber nicht hinwegtäuschen (vgl. BÜDEL 1977 und 1982, Fig. 34). BüDELs geomorphologische Interpretation dieses Bodeneises als Motor einer exzessiven Talbildung ist weit überzogen und weder auf „lebende“ noch auf ehemalige Periglazialgebiete übertragbar. 
Was die „Flächenbildung in den feuchten Tropen“ betrifft (siehe BüDEL 1958), so hatte der deutsche Bodenkundler FölSTER die alleinige Anwendung der Reliefanalyse 1964 in sehr feiner Form kritisiert (S. 413 und 421). Gleichzeitig demonstrierte er in unvergleichlicher Weise, wie man mit Hilfe von Form und Substrat den flächenbildenden Prozess der Pedimentation erschließen kann. Umgekehrt trug die prozessuale - nicht BüDELs klimatische - Erklärung von Fußflächen hervorragend dazu bei, die Substrate (Sedimente und Böden) zufriedenstellend zu beschreiben und zu verstehen - eine einmalige Rückkoppelung.

Nach ähnlichen Untersuchungen in Südost-Nigeria (Habilitationsschrift 1969) kam RohDEnburg zum Schluss, dass es „im Prinzip nur einen Flächenbildungsproze $\beta$, nämlich den der Pedimentation, gibt" (1970, S. 75; siehe auch Abb. 1). Auch mit seinem klimagenetisch-geomorphologischen Konzept trat Rohdenburg (1971, 1. Auflage) BüDEL entschieden entgegen.

Diese divergierenden Auffassungen zur Flächenbildung lösten intensive, aber oft auch polarisierende Auseinandersetzungen innerhalb der deutschen Geomorphologie aus. Sie sind an Schärfe und Leidenschaft kaum zu übertreffen. BüDEL reagierte mit: „Das natürliche System der Geomorphologie mit kritischen Gängen zum Formenschatz der Tropen“ (1971), welches er auch den Teilnehmern des 38. Deutschen Geographentages in Erlangen-Nürnberg überreichen ließ (1971a), welchem RoHDENBURG aber lediglich den Status eines „Programms“ zuwies (1971, S. XI; vgl. auch gesamtes Vorwort S. XI-XV).

BÜDEL hielt RohDENBuRg u.a. vor: „Er sucht die ganze Reliefbildung von der Bodenkunde aus zu lösen. Diese ist aber nur eine von vielen Hilfswissenschaften der modernen Geomorphologie“" (1971, S. 108; vgl. auch S. 78-82). Das verwundert. War es nicht BüDEL, der dann die tropischen „Arbeitsböden“ kreierte und der im Latosol den „eigentlichen Träger des „Mechanismus der doppelten Einebnungsflächen“, der diese Flächen erzeugt“, sah (1977, S. 99)? Auch seine exzessive Talbildung hat er mehr pedologisch (Bodeneis $=$ Eisrinde), denn geomorphologisch begründet (S.79ff.).

Die - fast panisch zu nennende - Ablehnung des Begriffsinhaltes von Pedimentation (Pediplanation) spiegelt sich meines Erachtens auch darin wider, dass BÜDEL 1963 noch eine eigenständige „Subtropische Pediment- und Talbildungszone“ auswies (Abb. 1), diese aber 1977 eliminierte (Fig. 13): Glacis und Pedimente seien jetzt Formen/Prozesse der „Flächenüberprägung“ (wobei die eigentliche Flächenbildung vorher durch die „doppelte Einebnung“ erfolgte, Anm. des Verf.). BüDEL führte aus, dass er Rohdenburgs Modellprofil der Pedimentation in seinem (BüDELs) Untersuchungsgebiet Indien nicht angetroffen hätte (1971, S. 76). Betrachtet man aber BüDELs einzige Mitteilung über den wahren Aufbau eines Bodenstandorts in Indien, nämlich sein Aufschluss-Foto vom 10. März 1964 bei Kolar (siehe 1965, Bild 2, noch mit „Spülpediment" bzw. 1977 und 1982, Foto 15; vgl. hier Abb. 2a), so erkennt man, dass die - in seiner graphischen Darstellung (Abb. 2 bzw. Fig. 43) als ,junger anthropogener Wasserriß“ bezeichnete - Abtragung schon erhebliche Breitenwirkung erreicht hat. Unterhalb solcher Stellen rückschreitender Ausräumung kann man dann immer Pedimentation in statu nascendi beobachten (KeHL et al. 2007, Abb. 3). Die Formbildung in nachstehender Abbildung $2 \mathrm{~b}$ stimmt daher mit dem RoHDEnburgschen Modellprofil prinzipiell überein (vgl. BüDEL 1971, Abb. 6). 


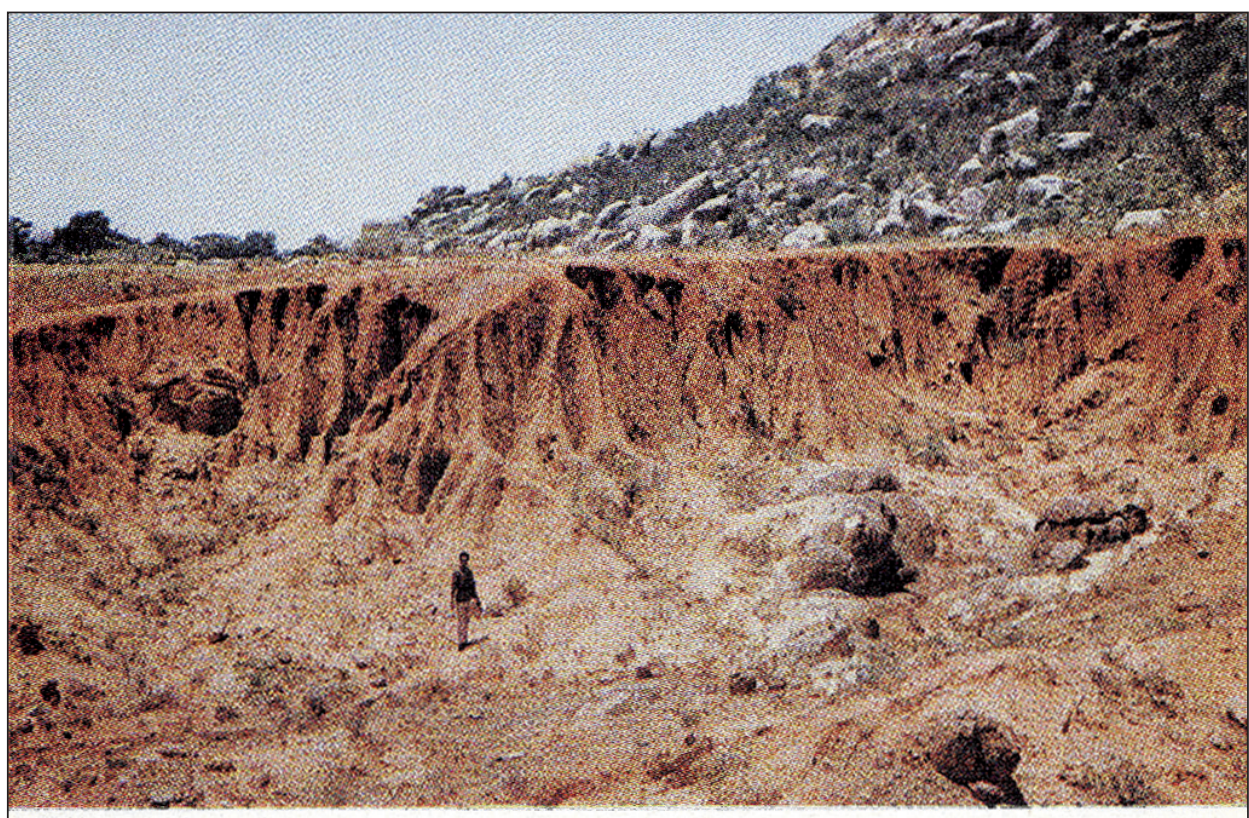

Bild 2. Unterschneidung eines Inselberges bei Kolar. Bis $5 \mathrm{~m}$ mächtiges, monogenetisches Rotlehmprofil auf cinem Spülpediment, in Vordergrund rechts tauchen Grundhöcker der Verwitterungs-Basisfläche auf.

Abb. 2a: BüDELs pedologische Interpretation einer „subkutanen Rückwärts-Denudation“ der „doppelten Einebnungsflächen“ (unverändert aus 1965)

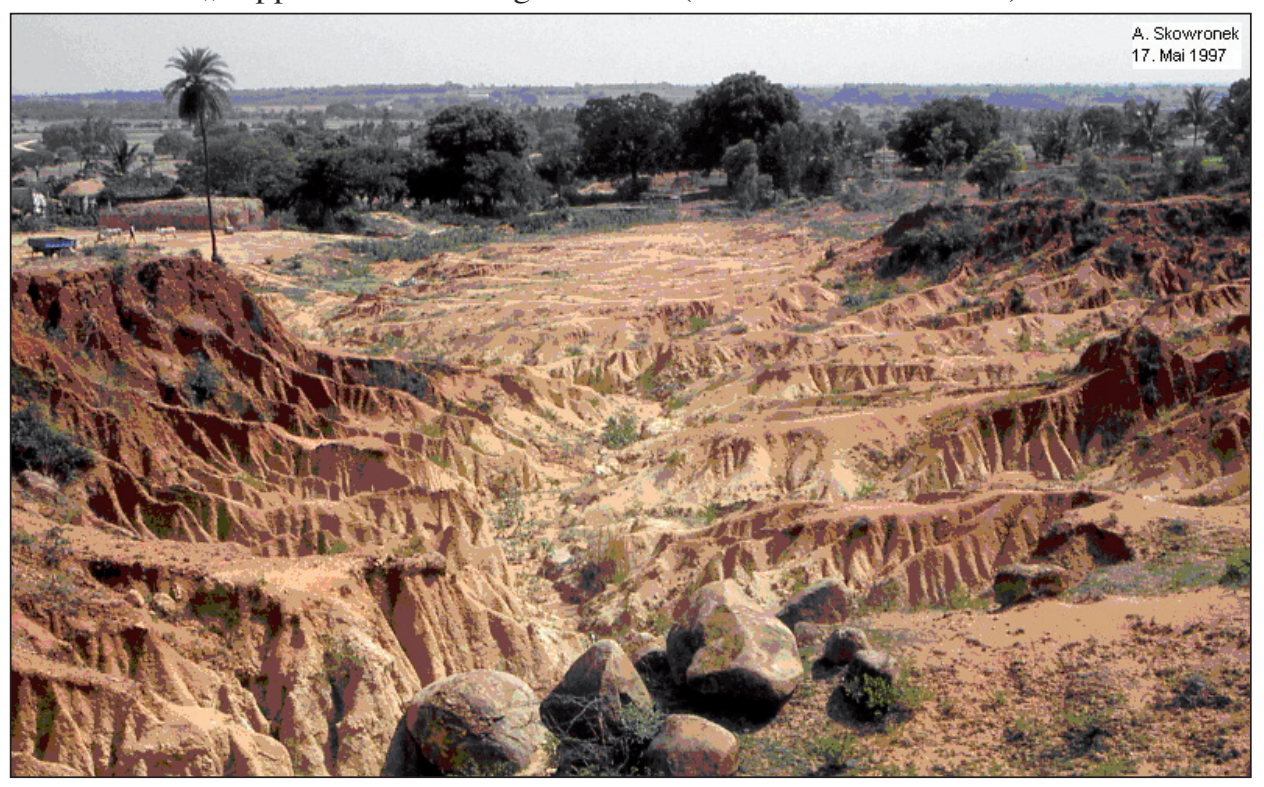

Abb. 2b: Aktuelle, anthropogen induzierte Pedimentation in einem Schwemmfächer und in Gneis-Saprolith nahe Standort Abb. 2a (aus KeHL et al. 2007, Abb. 3) 
BüDEL hob oft hervor, wie wichtig es bei geomorphologischen Arbeiten sei, eine „günstige Versuchsanordnung der Natur“ zu suchen und zu finden, um das Untersuchungsergebnis zu optimieren (vgl. 1977, S. 47 und 304). Für den relativ einfachen Prozess der Pedimentation - als „das sich zur Wasserscheide fortsetzende und auf die Kontributanten übertragende regressive Einschneiden der Flüsse“ (FöLSTER 1964, S. 413) - gibt es viele Beispiele, an denen man die Formbildung wie in einem Zeitraffer verfolgen kann (siehe z.B. BRADLEY 1940 oder SсHUMm 1962).

Zur Entstehung von mitteleuropäischen „Reliefgenerationen“ (BÜDEL) stelle man sich einmal „morphodynamische Aktivitätszeiten“ (ROHDENBURG) vor, in denen eine von der jeweiligen Abflussbasis gesteuerte - Hangabtragung auf allen (präexistenten) Reliefteilen gleichzeitig einsetze. Während des Tertiärs mit langfristig hohem Meeresspiegelstand und mit nur lokal/regional höherer Reliefenergie (Tektonik, Petrographie) würden ariditätsbedingte Pedimentationsphasen (vgl. auch STÄBLEIN 1972) weitgehende Einebnung bewirken, im Quartär dagegen wäre infolge eustatisch bedingter, rascher Tieferlegung der Vorfluter Pedimentation nur zeitabhängig und/oder nur in wenig resistenten Gesteinen möglich (vgl. „Breitterrassen“ Büdels und z.B. BRunOtTe \& GARLEFF 1989 oder BECK 1994). In Lößgebieten würde sogar anthropogen induzierte Bodenerosion Pedimente erzeugen (siehe Bork et al. 1998, S. 144-145).

Konsequenterweise müsste man dann von Reliefentwicklungsgenerationen sprechen, weil z.B. in unseren Mittelgebirgen - fehlende Flusseintiefung vorausgesetzt - noch viele Pedimentationszyklen nötig wären, um eine Fastebene zu erzeugen. Das würde der, auf dem Konzept der BüDELschen „Reliefgenerationen“ basierenden, hervorragend gelungenen Darstellung der „Landschaftsformen der Erde“ von Busche et al. (2005) keinen Abbruch tun, zumal die Autoren den „Mechanismus der doppelten Einebnung“, also den Flächenbildungsprozess per se, nicht verifiziert sahen (S. 27). Auch würden BüDELs Einebnungsflächen nicht mehr so unnatürlich glatt und nicht mehr „so rücksichtslos über alle Gesteinsunterschiede hinweg“ greifen wie z.B. die „Fränkische Gäufläche“ über den triadischen Schichtenbau (siehe 1957, Abb. 9. und S. 211). Und die ausgeprägten Hangkonkavitäten der Geroldshauser Höhe (324 m) südlich Würzburg wären das, was ihnen BüDEL namentlich zuschrieb: „Pedimente“ (Abb. 8b). Schließlich müsste nicht jeder Rotlehm auf einer Rumpffläche zu dem Boden avancieren, der diese Fläche gebildet hätte - und nicht jedes rote Solum auf einem Talhang oder Talboden müsste ein Sonderfall sein.

Bodenkundliche Befunde aus BüDELs indischem Arbeitsgebiet lassen sich auch nicht mit seinen Vorstellungen von Aufbau, Genese und Dynamik der Pedosphäre in den Tropen („Arbeitsböden“) vereinbaren (1977, S. 102-104).

Der indische Regur, den BüDEL (1977, S. 98-99) geomorphologisch unbewertet ließ („Arbeitsboden“ oder „Ortsboden“), verdankt nach ScHEFFER et al. (1959/60, siehe Diss. Fölster 1960) seine Existenz einer besonderen Bicarbonatmetabolik und kommt in Granit-Gebieten unterhalb rotlehmbedeckter Hänge als „Hangfuß-Regur“, in etwas größerer Entfernung auch als „Tal-Regur“ vor (S. 309). Letztere Situation ist ca. 2 km westlich Kolar - unweit Büdels Aufschluss (s.o.) - gegeben: Das an der Antarganga-Quelle im Inselberg (1226 m) ansetzende Tal kreuzt terrassenartig den mit Schwemmfächern bedeckten Inselberg-Fuß und läuft auf die vorgelagerte Pediplain (ca. 900 m) aus (KeHL et al. 2007, Abb. 1 und 2). Alle Böden, die Hang-,,Rotlehme“ 
(Alfisols/Luvisols), der „Tal-Regur“ (Entic Haplustert/Vertisol) sowie die Böden auf den Bodensedimenten der Schwemmfächer und der Pediplain (schwach entwickelte Alfisols/Luvisols) sind „Ortsböden“ im Sinne Ramanns (s.o.) - aber auch im Sinne BüDEls (s.o.), weil sie nicht an der Reliefbildung (Tal und Fläche) beteiligt sind. Die Geomorphogenese hat die Reliefposition und das Ausgangsmaterial dieser Böden prä-disponiert.

Nach umfassenden Beobachtungen in Südindien wandte sich BRONGER (1985) gegen BüdELs $(1965,1977)$ Konzept eines 4-10 m mächtigen „monogenetischen Rotlehms“ (welcher als „Arbeitsboden“ die „doppelte Einebnung“ und die „,subkutane RückwärtsDenudation“ bewerkstelligen soll, Anm. d. Verf.), weil die in Frage stehenden Böden selten mehr als 1,5 m dick werden, und weil sie „Paläoböden“ aus einer wesentlich feuchteren Klimaperiode (als heute) darstellten. Und SEUFFERT, Würzburger Mitarbeiter und Habilitand von BüDEL, plädierte hinsichtlich Flächenbildung für eine „spezifische Abfolge von Klimaten“, nämlich für „,eine feuchte Materialaufbereitungsphase“ und für „eine semiarid/aride Transport- und Flächenbildungsphase“ (1986, S. 212). Die - auf einer Habilitationsschrift und einer Dissertation beruhende - verwitterungskundlichpedologische Einschätzung von BRÜCKNER \& BRUHN (1992) kam zum Ergebnis: Die Einebnung der Tamilnad-Fläche benötigte eine vielfache Zyklizität „,von Tiefenverwitterung unter tropisch-humidem Klima und nachfolgendem flächenhaftem Abtrag durch Spüldenudation unter (semi)aridem Klima“ (S. 43). Schließlich bestätigte SpäтH (1995) die geringe Mächtigkeit, den überwiegenden Reliktcharakter und die teilweise vorhandene Schichtigkeit der Böden (u.a. Schutt) im Kristallin des Dekkans. Umfangreiche laboranalytische Untersuchungen folgten mit der Dissertation von LAUFENBERG (2003).

Im südamerikanischen Teil der „randtropischen Zone exzessiver Flächenbildung“ Büdels erkannte BıBus (1983), dass die Bodendecke von Manaus bis Rio de Janeiro mehrschichtig aufgebaut ist, was sich nur mit - geomorphologisch wirksamen - Klimawechseln in jüngerer geologischer Vergangenheit erklären lasse.

Den abstrahierenden Charakter von Modellen betonend, verglich die BüDEL-Schülerin Bremer 1993 das Kingsche Konzept der - weitgehend nicht-klimatischen - Reliefeinebnung (durch Hangrückverlegung und Pedimentation, vgl. KING 1953; siehe auch Zitierung bei BüDEL 1977, S. 117 und 285) mit dem Modell der „doppelten Einebnung“ (or „etchplanation“) von BüDEL $(1957,1977)$ und präferierte letzteres, u.a. weil: "It is a great advantage that the model of BÜDEL is an open system, open to changes of energy due to climatic change and/or uplift" (S. 194). Und in seiner - sonst souveränen und gedankenreichen - „Geomorphologie der Tropen“ ging WiRTHMANN (1987, S. 112) bei der Abstrahierung von Flächenbildungstheorien so weit, dass er die, während der Pedimentation (im Sinne RohDENBurgs) ablaufenden, „Bodenumlagerungen“ zu „Ausführungsbestimmungen“ zum Mechanismus der doppelten Einebnungsflächen BüDELs (1957) erklärte - und degradierte.

BÜDEL (1957) implizierte für den „Mechanismus der doppelten Einebnungsflächen“ in den Tropen immer eine Gleichzeitigkeit von Pedogenese und Geomorphogenese, nie öffnete er sein Modell für einen geomorphologisch relevanten Klimawechsel, im Gegenteil, er ging von einem schon sehr lang andauernden Klimazustand aus, der oben genannten „Mechanismus“ ermögliche (siehe 1963, Fußnote 17; 1977, besonders S. 116-117 und Fußnote 39). Seine früheren Einlassungen zur Polygenese von 
Tropenböden und zu Klimawechseln setzte er nur pedologisch um: Letztere hätten einen „diskontinuierlich abgewandelten Reifeprozeß“ der Böden erzeugt (Büdel 1965, S. 16-17). Es war Rohdenburg (1970), der das Kingsche Modell um die entscheidende klimageomorphologische Komponente, nämlich um pedo- und geomorphogenetisch verschieden wirkende Klimate, d.h. Klimawechsel, erweiterte (was WirThMANN dann 1994 auf S. 66-67 voll anerkannte; siehe aber auch BREMER 2003, S. 475). Das Konzept ist ergebnisoffen, weil die Hangentwicklung letztlich vom Verhalten der Abflussbasis und vom (jeweiligen) Zustand der Vegetation abhängt (vgl. ROHDENBURG 1989).

Zwischenfazit. Die schon 33 Jahre zuvor von CREDNER (1932) angedachte geomorphologische Duplizität der Abtragung wurde von BüDEL (1965) in zwei - auf synchrone Pedogenese (im Mittel 4-6 m mächtiger „monogenetischer Rotlehm“ und „Arbeitsboden") gestützte - Einebnungsflächen umgesetzt und um die - aus der Karstmorphologie (Krebs, LehmanN) entlehnte - Karstdenudation/Lösungsunterschneidung (= „Subkutane Seiten-Denudation“ mit „Doppel-Arbeitskante“) ergänzt. Beides ist bodengeomorphologisch unhaltbar. Alle Ableitungen und Abstraktionen der „doppelten Einebnungsflächen“ beruhen auf falschen bodenkundlichen und auf falschen geomorphologischen Annahmen.

Will man das Verhältnis von Pedo- und Geomorphogenese - über stratigraphische Erkenntnisse hinaus - weiter erhellen, so bedarf es eines tieferen Bodenverständnisses. Zum Beispiel würde nach FRÄNZLE (1977) die - geomorphologisch entscheidende - Beziehung von horizontaler Schubspannung des Oberflächenabflusses und Scherwiderstand des Bodens auch durch (syngenetische) bodeninterne Krustenbildungen (Fe, Al, Si) gesteuert, weil diese die Infiltrations- und Perkolationskapazität lokal reduzierten - dies besonders in „lehmigen“ (= Si-reichen und plastischen) Luvisols. Die Folge könnten Wasserstau und Exfiltration am Hang mit Bodenabtrag unter Herausarbeitung einer kontinuierlich verhärtenden Fe-Kruste bzw. einer Krustenstufe sein. Derartige Stufen dienten dann dem Oberflächenabfluss als Denudationsbasen - mit der Tendenz zur Flächenbildung (durch Pedimentation, der Verf.). „Vererdete“ (= stark Si-verarmte) Varianten der Ferralsols, Acrisols und Luvisols mit hoher Infiltrations- aber niedriger Feldkapazität neigten dagegen mehr zur „Kerbtal- und Röhrenerosion“ (FRÄNZLE 1976, S. 181; siehe auch BREMER 1994).

Von großer geomorphologischer Weitsicht erwies sich die Einführung des Begriffes „quasi-natürliche“ Oberflächenformung durch MorTensen (1954/55), weil damit manifestiert wurde, dass geomorphologische Formen trotz anthropogener Ursache in gleicher Weise entstünden wie unter natürlichen Bedingungen. Das gelte besonders für die weltweit wirkende Bodenerosion durch Wasser. Dass auch dieser Prozess letztlich zur Ausbildung von Stufen und anschließenden Hangverebnungen (= Pedimentation, der Verf.) führen muss, zeigten in Deutschland schon 1950 die aufschlussreichen Untersuchungen und Hangprofile von WANDEL. Daher ist nicht zu verstehen, warum BüDEL (in einer hochemotionalen Arbeit) die prozessual-geomorphologischen Aussagen Rohdenburgs (1969) zur Bodenerosion auf Rumpfflächen in West-Afrika folgendermaßen kolportierte: „Jüngste oberflächliche (und oft schon wieder verhüllte) Ansätze zur Zerstörung von Rumpfflächen werden zu deren Bildungs -Vorgängen 
erklärt. Hier liegt eine Vortäuschung (BüDEL berichtigte: „Vertauschung“, der Verf.) von räumlichen und zeitlichen Dimensionen in einem Grade vor, der allen wissenschaftlichen Prinzipien widerspricht“ (1971, S. 79). Später konnte SEuFFERT (1988, besonders Abb. 6 und 7) für Südindien, welches nach BüDEL (1971, S. 31) weitgehend von Bodenerosion verschont geblieben sein soll (vgl. jedoch auch 1965, S. 14 und 17), eindrucksvoll aufzeigen, wie Vegetationszerstörung durch den Menschen die Relationen von raum/zeitvariaten Intensivniederschlägen, Interzeption/Evaporation, Infiltration/Oberflächenabfluss, Grundwasserabfluss und Gerinneabfluss verändern kann: Die geomorphologischen Prozesse im „,anthropogen veränderten Zustand“ des Abtragungssystems führten zu Hang- und Gerinnebettformen, die man mit RoHDENBURG (1969, S. 79) unschwer als „Hangpedimente“ bzw. als „Talbodenpedimente“ bezeichnen könnte. Warum sollte nicht auch eine „Rumpffläche“ auf diese Art und Weise entstehen, z.B. durch zyklische Wiederkehr klimabedingter Pedimentationsphasen?

Es verwundert in der Tat, dass BüDEL die Anwendung des - zwar aus den Trockenräumen stammenden, aber geomorphodynamisch definierten - Pedimentations-Begriffes (Zurückweichen einer Stufe unter Bildung einer Fußfläche) so massiv ablehnte (,Suggestion des Terminus“) und glaubte, dass die „überall auf der Erde“ vorkommenden „konkaven Hangabschwünge ... dann jeweils der besonderen morphodynamischen Erklärung“ bedürften (1971, S. 17-18; vgl. dazu jedoch KING 1957). Was ist - im geomorphologischen Ergebnis - der Unterschied zwischen seinem Hang(entwicklungs)modell aus Südindien (1986, Fig. 5) und dem aus SE-Spitzbergen (1977, Fig. 30)? Die hier in Abbildung 3 unverändert übernommenen, im jeweiligen Text von BüDEL mit zahlreichen begrifflichen Hilfskonstruktionen versehenen Graphiken zeigen beide eine Hangkonkavität, die man problemlos mit dem Terminus „Pediment“ belegen kann. Denn worin besteht der prinzipielle Unterschied zwischen dem ,aktiven HangfußEffekt“ im Periglazialraum (BüDEL 1970b, S. 24) und dem „zentrifugalen Hangfußeffekt “ in den Tropen (BüDEL 1986, S. 37ff.)? Meines Erachtens unterlag BüDEL zu sehr der Vorstellung, die Abtragungsformen in Festgesteinen (Flächen und Täler) müssten auch ein unterschiedliches geomorphogenetisches Bildungsklima widerspiegeln. Doch schon sein Berliner Lehrer Albrecht PENCK (1858-1945) hatte erkannt, dass sich die korrelaten Sedimente dafür besser eignen als die Erosionsformen, weil diese nur die Summierung der Effekte von Klimawechseln darstellten (A. PENCK 1905, S. 174). BüDEL hat auch nie erklärt, wie aus einem Tal eine Fläche entsteht bzw. entstehen könnte, was in tropischen Gebirgen oder nach der „Zerschneidung“ von Rumpfflächen schon einer geomorphologischen Frage würdig gewesen wäre (siehe dazu aber WIRTHMANN 1977, 1981). Er setzte Flächen und Täler praktisch als gegeben voraus. „Exzessive Flächenbildung“ und „exzessive Talbildung“ wirkten deshalb eher wie Abtragung ohne Formung (vgl. dazu Mortensen 1963).

Zusammenfassung. Der prinzipiell richtige Gedanke, das fluviale Abtragungsrelief - prozessual und genetisch - von der steuernden Vorflut aus zu betrachten (DAVIS, Louis), bedurfte eigentlich nur noch eines besseren hydraulischen Verständnisses von Oberflächen- und Gerinneabfluss, um Tal-, Hang- und Flächenbildung realitätsnah $\mathrm{zu}$ interpretieren. BüDEL ging jedoch von der fertigen Peneplain aus und leitete allein aus der Form tertiärer Rumpfflächen direkt einen Bildungsprozess, nämlich ,eine im 


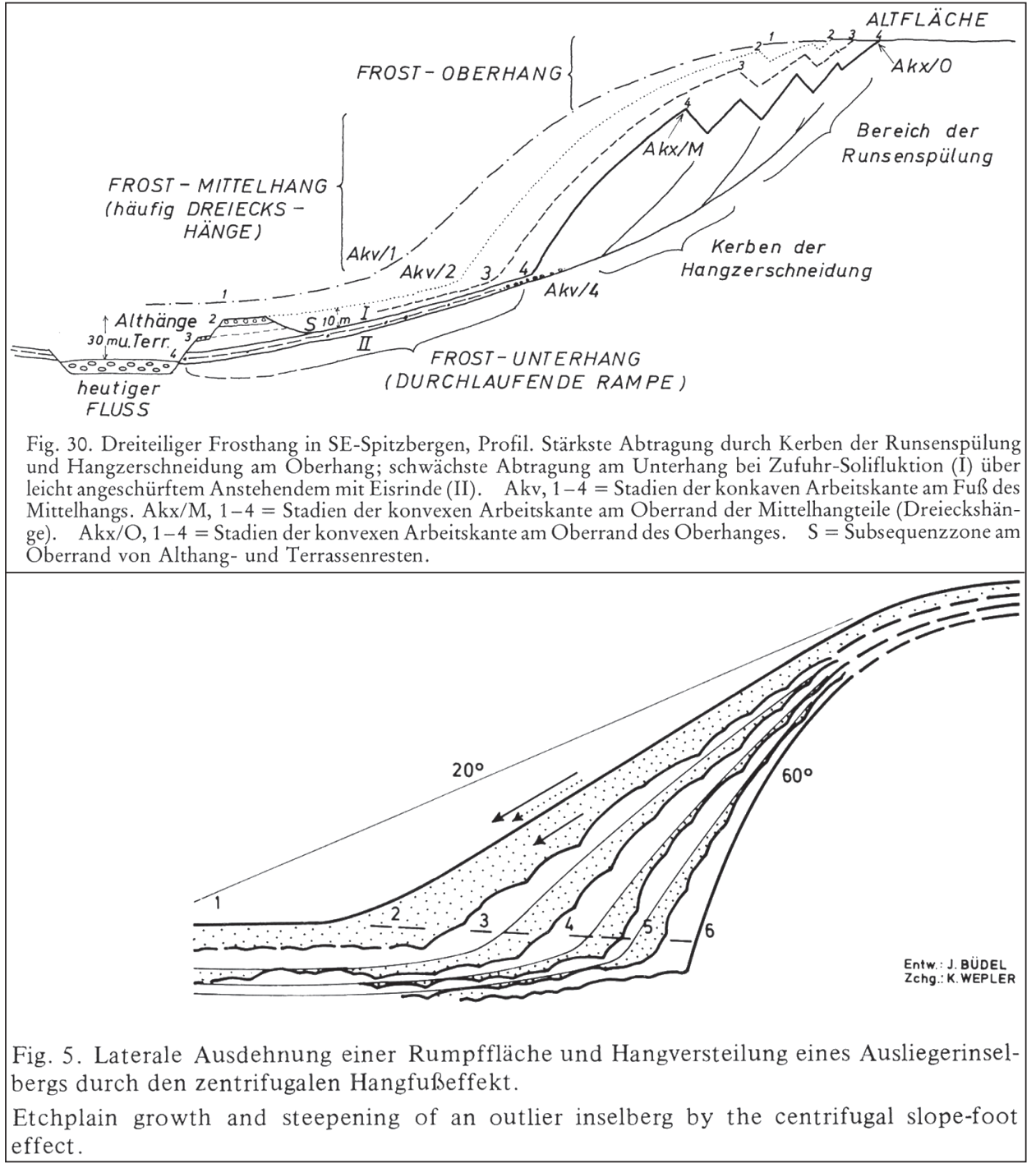

Abb. 3: BüDELs Hangentwicklungsmodelle der „,subpolaren Zone exzessiver Talbildung“ (oben) und der „randtropischen Zone exzessiver Flächenbildung“ (unten), unverändert aus 1977 (S. 73) und aus 1986 (S. 37).

Niveau der Flussläufe auftretende Flächenspülung bzw. Grundwasserdenudation“, ab (1935, S. 145). Im Gegensatz dazu: „Die heutige Zertalung ist ein genetisch davon ganz unabhängiger, späterer Vorgang, der sich unter grundsätzlich anders gearteten Voraussetzungen der Abtragung abgespielt haben muß oder noch abspielt" (S. 144). Da „die tropische Verwitterungsform der Kaolinisierung fast durch das ganze Tertiär hindurch anhielt“" (S. 146; zu einer differenziellen Kaolinisierung siehe STREMmE 1910), 
kam für die Talbildung nur ein pleistozän-kaltzeitliches Klima in Frage. Der Weg zu den tropischen „,doppelten Einebnungsflächen“ und zum periglazialen „EisrindenEffekt" - als eigenständigen Formungsmechanismen - war damit vorprogrammiert. Beide - geistig gleichsam von oben aufgezwungenen - „Prägestöcke“ integrierte BüDEL aber nicht in das hydraulische System: Diese verwitterungskundlich-pedologisch motivierte Idee von der Genese des fluvialen Abtragungsreliefs (vgl. besonders BüDEL 1963, S. 273) sprach dem Abfluss praktisch jedwede eigenständige Formungskraft ab. BüDELs Vorstellung von der „Vorfluter"-Rolle (1969, S. 14) war ein Rückschritt gegenüber DAVIs und konnte auf Dauer nicht überzeugen. Es überrascht deshalb nicht, dass BüDEL letztlich auch aus seinem engeren Umfeld heraus widerlegt wurde (s.o.).

Auf der anderen Seite gelang dem 34 Jahre jüngeren ROHDENBURG durch modellhafte Weiterentwicklung älterer Ideen und in überzeugendem Widerspruch zu BüDEL ein entscheidender Durchbruch bei der Deutung des fluvialen Abtragungsreliefs, weil er eustatische Meeresspiegelschwankungen und das Verhalten der Abflussbasis (Eintiefung, Aufhöhung, Gleichbleiben) mit der Hangentwicklung verknüpfte. Da er gleichzeitig Bodenbildungen als Indikator geomorphologischer Stabilität integrierte, gelang ihm auch eine differenziert-klimatische Deutung des Reliefs. „Talbodenpedimentation“ und „Hangpedimentation“ (1969, S. 79ff.) stellen - hydraulisch begründet - derzeit das beste Erklärungsmodell für Reliefeinebnung dar. Tal- und Flächenbildung sind darin kein Gegensatz.

Nach BremER (1984, S. 281) erfuhr die deutsche Geomorphologie jedoch 1948 ihren entscheidenden Wendepunkt mit BüDELs „,Das System der klimatischen Geomorphologie“ (1950), welche als „Klima-Geomorphologie“ bis zu seinem Tod dominierte (der Verf.). Diese fand so viel Akzeptanz, ,that climatic geomorphology is sometimes called classical or traditional geomorphology“ (BREMER 1989, S. 96).

\subsection{Internationale Rezeption}

Wiedergabe und Diskussion der internationalen Wahrnehmung des wissenschaftlichen Werkes von Julius BüDEL müssen notgedrungen unvollständig und gegebenenfalls unbefriedigend bleiben, einmal, weil sich offensichtlich nur sehr wenige Arbeiten mit dem Gesamtwerk auseinandersetzten, zweitens, weil BüDELsche Erkenntnisse auch in anderen - zunächst nicht vermuteten - geowissenschaftlichen Zusammenhängen zitiert wurden. Der Verfasser ist sich möglicher Defizite und Unzulänglichkeiten bewusst.

1984 publizierte Kiewietdejonge (Department of Geography, San Diego State University, San Diego, California, USA) eine umfassende Darstellung (64 S.) der Forschungsarbeit von BüDEL. Das Manuskript war schon vor der Übersetzung der „Klima-Geomorphologie“ ins Englische (siehe BüDEL 1982) fertiggestellt und BüDEL auch bekannt: "Eight months prior to his death he read and fully approved the present as well a second paper (to be published in the next issue) suggesting only minor modifications, which have been observed" (Kiewietdejonge 1984, S. 245). Der Autor hielt sich dabei fest an die Gliederung der „Klima-Geomorphologie“ von 1977. Obwohl er eingangs zur Forschungsleistung BüDELs feststellte: "This thesis is either ignored because of the language barrier, misunderstood, or even opposed outside of German 
speaking Europe" (S. 218), erfährt man im Text nichts über Missverständnisse oder Gegenmeinungen. Die Studie eignet sich meines Erachtens aber als Kommentar der „Climatic Geomorphology“ BüDELs (1982) und damit auch als Grundlage für eine internationale (englischsprachige) Diskussion seiner Ideen.

In einer jüngst erschienenen Rezension beschrieb Migon (Department of Geography, University of Wrocław, Wrocław, Poland; Secretary General of the International Association of Geomorphologists) BüDEL als einen Forscher, der Visionen entwickeln konnte, wenn es darum ging, "to understand landscapes as a whole" (2006, S. 100). Dazu hätte dieser geomorphologische Prozesse immer in Kombination und in ihrer gegenseitigen Wechselwirkung gesehen. Er hätte auch erkannt, dass heutige Landschaften nicht ohne das Verständnis der Vergangenheit erklärt werden könnten, dafür seien die Landformen selbst eine wichtige Quelle (relief generations). Weiterhin hätten „environmental changes“ (S. 100) fundamentalen Einfluss auf die Landschaftsentwicklung, und schließlich hätte BüDEL durch Vergleichsuntersuchungen in Spitzbergen und Indien die pleistozäne und tertiäre Morphogenese Mitteleuropas aufklären können. Als Schwächen sah Migon an: 1. eine Überbetonung der klimatischen Kontrolle der Reliefbildung, 2. die Großskaligkeit der klima-morphologischen Zonen, in denen endogene Kräfte nicht berücksichtigt würden und 3. eine heute nicht mehr befriedigende Methodik bei der Untersuchung der Reliefvergangenheit. Insgesamt sei BüDEL aber ein Meister mit , an eye on the landscape' gewesen, das heutige Analytiker nicht besäßen, aber dennoch bräuchten (S. 102).

Stellvertretend für wohl mehrere Lehrbücher der Geomorphologie, welche die „doppelten Einebnungsflächen“ aufgenommen haben, möge die „Geomorphology in the tropics" des britischen Geomorphologen Thomas (1994) stehen. Darin beschrieb der Autor unter der Überschrift „Etching Processes and Landform Development“ verschiedene Konzepte der Flächenbildung, an erster Stelle das von BüdEL (S. 287-290). Die essentiellen Bestandteile der ,double planation surfaces “ BüDELs in den „,seasonally wet tropics" seien (S. 288, wörtlich):

(1) soil thicknesses of 3-30 m;

(2) homogenisation of the soil profile indicating a constant, dynamic evolution;

(3) a sharp transition from weathered to fresh rock over wide-jointed, quarziferous rocks, indicating intense weathering;

(4) the widespread existence of a deeper zone of decomposition 100-150 m (perhaps $200 \mathrm{~m})$ thick.

Die von BüDEL (1982, S. 122, Fußnote 29) für Rumpffläche gewählte englische Übersetzung ,etchplain“ sah TномAs verifiziert, wenngleich er auch den großen Facettenreichtum dieses Konzepts vor Augen hatte (1994, S. 287-310).

Sieht man einmal von den nicht weiter erläuterten pedologischen Implikationen (2) ab, so müsste nach dem Konzept der „etchplanation“ eine neue ,planation surface“ exponiert werden, wenn der Regolith (= Solum, gegebenenfalls Sedimente und Saprolith) vorher entfernt wurde. Der Habitus der neuen Fläche ist aber in der Regel weit entfernt von einer (geomorphologisch) ebenen Fläche. Man errechne einmal - analog 
der oberirdischen Reliefenergie - die Höhenunterschiede der Festgesteinsoberflächen in der BüDELschen „Verwitterungs-Basisfläche“ („Basal weathering surface“) und setze sie - maßstäblich - in eine kryptogene Reliefenergie um. BüDEL selbst gab 1965 subkutan „,bis zu 20 m Reliefenergie“ an (S. 15), was er allerdings nicht mit seiner eigenen Definition von „Ebene“ oder "Fläche“ in Beziehung brachte (vgl. S. 9-10, Anm. 2). Es würde terminologisch etwas vorgetäuscht, was nicht existiert. Deshalb riet MaвButT schon 1961 von der Benutzung des Begriffes , basal surface‘ ab und forderte stattdessen die Beibehaltung des Terminus, weathering front ${ }^{\star}$.

Interessanterweise fanden sich auch zwei Zitierungen von BüDEL (1982) bei der Lagerstättenprospektion in den Tropen und Subtropen wieder (LесомтE 1988; ButT \& ZEEGERs 1992). Der Zusammenhang mit geomorphologischen Fragestellungen erklärt sich aus dem Dispersionsgrad des gesuchten Rohstoffs (z.B. Gold) im Regolith, also in der - zumeist mehrere Zehner von Metern mächtigen - Lockerdecke über unverwittertem Festgestein. Bestimmte Komponenten des Regoliths wie z.B. „stone lines“ können den Rohstoffgehalt des Liegenden signalisieren (abgesehen davon, dass der Regolith selbst zu einer Lagerstätte angereichert sein kann).

In diesem Sinne machte Leсомте (1988, S. 38) bei der geochemischen Prospektion u.a. auf Gold in Gneisen und Amphiboliten des präkambrischen Grundgebirges Westafrikas (Gabun) die Fig. 13 ,The morphoclimatic zones of the present (excluding the high mountains)“ von BüDEL (1982) zur Basis seiner eigenen Fig. 1 „Schematic world distribution of stone line profiles areas, related to tropical climates (after Budel, 1982)“ - eine ignorante Verwechslung oder eine unverständliche Verfälschung. Die „tropical climates“ wurden als „Equatorial zone“, „,Tropical zone“ und "Desertic zone“ gekennzeichnet, andererseits erfolgte aber auch keine geochemische Interpretation des BüDELschen Regoliths zwischen „Wash surface“ und „Basal weathering surface“ (vgl. BüDEL 1982, Fig. 41 oder 43).

ButT \& ZeEgers (1992, Fig. I.1-2) übernahmen ebenfalls die oben genannte Karte BüDELs, zwar etwas verkürzt und verändert, aber ohne Sinnentstellung: „Present morphoclimatic zones. Redrawn from Budel (1982)“. Vor dem Hintergrund der Erkenntnis, dass eine sekundäre geochemische Dispersion z.B. der Erze entscheidend von pedologischen und geomorphologischen Prozessen abhänge, hoben die Autoren bei der Einschätzung des geomorphologischen Einflusses das BüDELsche Konzept der „dual planation surfaces“ mit der „ground surface“ („Spül-Oberfläche“, der Verf.) und der „weathering front“ (,Verwitterungs-Basisfläche“, der Verf.) hervor, "because the chemical processes at the weathering front are more rapid than the erosional processes at the denudation surface" (ButT \& ZeEgers 1992, S. 11).

Was die internationale Wahrnehmung BüDELs zur Periglazial-Geomorphologie betrifft, so kann auf eine sehr umfassende, mehrere Sprachen (auch Deutsch) berücksichtigende Forschungsgeschichte Spitzbergens von Humlum et al. (2003) verwiesen werden. Dort fand BüDEL keine Resonanz. Bei Holmsen (s.o.) wurde anerkannt, dass "he was probably the first to demonstrate a late Holocene age for permafrost and ground ice at low altitudes in Svalbard" (S. 192). 


\section{Stellung und Bedeutung der Büdelschen Klima-Geomorphologie}

In seiner Einleitung zum Sammelband „Klimatische Geomorphologie“ machte RATHJENS (1971, S. 2-3) gleich klar, dass diese zwar „eine besondere Betrachtungsweise“ besitze, andere Teilgebiete wie die „Geologische oder Tektonische Geomorphologie“ bzw. die „Anthropogene Geomorphologie“ aber gleichberechtigt seien. Dies ließe sich aus BüDELs Begriffen „Petrovarianz und Epirovarianz“ nicht ableiten, weil BüDEL damit dem Klima einen „Bedeutungsvorrang“ einräume. RATHJENS „eigener Vorschlag einer klimatisch-geomorphologischen Zonierung der Erde“ (sieben Zonen) war gegenüber BüDEL abgewandelt, im Prinzip folgte er aber dessen Konzept, indem er der Verwitterung und der Bodenbildung indirekt eine (diffuse) formbildende Wirkung zuschrieb, z.B.: „C. Formengruppen der Zone der seichten Ortsböden“ (mit drei Unterzonen), „F. Formengruppen der Zone der Flächenspülung bei intensiver tiefgründiger Verwitterung, der Fußflächen und Inselberge“ oder „G. Formengruppen der Zone der tiefgründigen Ortsböden mit starker Durchfeuchtung “ (1971, S. 13-18).

Abgesehen von der unzulässigen Benutzung des Begriffes „Ortsböden“ (s.o.) und der wenig kohärenten Begrifflichkeit, wurde erkennbar, dass die „Klimatische Geomorphologie“ zwei grundverschiedene Vorgänge nicht zu trennen bzw. nicht in eine überzeugende Beziehung zu setzen vermochte: Verwitterung und Bodenbildung auf der einen Seite und Abtragung (Abfluss) auf der anderen (wobei noch zu berücksichtigen wäre, dass Verwitterung nicht gleich Bodenbildung ist und umgekehrt Bodenbildung nicht nur Verwitterung). Schon Walther PENCK (1924) hatte sehr genau zwischen einer lithologisch-klimatisch kontrollierten „Gesteinsaufbereitung“ und einer nicht-klimatischen, flächenhaften Abtragung unterschieden (S. 59). Bei einer klimatischen Deutung des fluvialen Abtragungsreliefs oder bei der Forderung unterschiedlicher Formungsmechanismen hätte deshalb eine wichtige Frage lauten müssen: Gibt es klimatische Unterschiede des formbildenden Agens, also des Abflusses bzw. der Abflussdynamik (Hänge, Vorfluter)? Es hatte jedoch den Anschein, dass man zur Begründung und Legitimation einer „Klimatischen Geomorphologie“ lieber Abtragungsobjekte - vorwiegend klimatisch speziierte Teile des Regoliths - heranzog als Kenntnisse zum Abflussverhalten selbst. Dabei hätte spätestens seit KING (1957) erkennbar sein müssen, dass die Hangformung einer Eigengesetzlichkeit des Abflusses unterliegt und nicht der Steuerung durch ein bestimmtes Klima. Das zeigten im Prinzip auch die Spülmodelle aus der - bahnbrechenden - Dissertation von GossmanN (1970), was BüDEL in seinem Vorwort aber nicht wirklich anerkannte (1970, S. 1-5).

In diesem Zusammenhang erhebt sich in der Tat die essentielle Frage: „Klimaoder Prozessgeomorphologie?" Mit dieser Frage gingen Buch \& HeINE 1988 dem spätpleistozänen und holozänen Gerinneabfluss am Beispiel der Donau nach. Die Autoren reduzierten anhand von sedimentologischen (und malakologischen) Befunden die Monokausalität von klimageomorphologischen „Reliefgenerationen“ auf den Maßstab „Glazial-Interglazial-Zeiten“ (S. 18; vgl. aber Bremer 2004a, S. 843). Die Reliefformung der dreistufigen „Talgrundterrasse I“ (= Niederterrasse des Würms) und der darin tief (bis 23 m unter die Schotteroberkante der Niederterrasse) eingelassenen, ebenfalls dreistufigen „Talgrundterrasse II“ (= Talaue des Holozäns) wurde dagegen mit einer - weitestgehend klimaunabhängigen - Eigengesetzlichkeit des 
Gerinneabflusses und den damit verbundenen ,autozyklischen Akkumulations- und Erosionsphasen“ begründet. Die Irreversibilität anthropogener Veränderungen derartiger (offener) fluvialer Systeme wurde herausgestellt, auf die Möglichkeiten einer angewandt-geomorphologischen Forschung hingewiesen.

Umgekehrt kann man aber auch mit RoHDENBurg et al. (1976) z.B. für den Denudationsbereich fragen: „Sind konkave und konvexe Hänge prozessspezifische Formen?“ Nach „Hangentwicklungssimulationen mittels EDV“ werde „,die hangeigene Entwicklungstendenz bei Abspülung“ stark vom „Hang-Vorfluter-Ungleichgewicht“ bestimmt (S. 113-114). Bezüglich des Verwitterungseinflusses auf Tal- und Flächenbildung könnte man mit RoHDENBuRG (1989, S. 130-134) dann folgendermaßen argumentieren: In Gebieten mit mechanischer Verwitterung und überwiegend Grobmaterial an den Hängen würde das oben genannte Ungleichgewicht schon bei geringer Hebung bzw. Vorfluterabsenkung ungleich größer werden als in Gebieten mit intensiver chemischer Verwitterung (oder geringer Gesteinsresistenz). Der „Dislokationsschwellenwert, der zwischen Talbildung einerseits und Flächenbildung andererseits entscheidet" (S. 133), würde damit im ersten Fall auch viel schneller erreicht, mit der Folge einer Zerschneidung (Talbildung), während im zweiten Fall (noch länger) Flächenbildung durch Hangpedimentation erfolge. „Es handelt sich allerdings nicht um Bereiche mit klimabedingt anderen Formungsmechanismen, wie BüDEL meinte, sondern um Zonen unterschiedlicher Prozeßkombinationen“ (Rohdenburg 1989, S. 131). Zum prinzipiell gleichen Ergebnis gelangte der amerikanische Bodengeomorphologe RuHE (1975) nach einem großräumigen Vergleich der Hangentwicklung unter verschiedenen Klimaten.

Im Rahmen einer „Climatic Geomorphology“, die BREMER (2004) aber streng von einer „Climato-genetic Geomorphology“ getrennt wissen wollte, sei das Konzept BüDELs (1982) im Wesentlichen als eine geographische Version der Geomorphologie anzusehen (Goudie 2004). Vor allem hätten die häufigen und schnellen Klimawechsel des Quartärs sowie die ,very different climates of the Tertiary“ jede einfache Klima/ Landform-Beziehung maskiert. "For this reason, Büdel (1982) attempted to explain landforms in terms of fossil as well as present-day climatic influences" (S. 163).

Es ist das genuine Recht der Geographie, Grenzen zu suchen und Grenzen festzulegen. Das hat BüDEL selbst einmal zur richtigen Erfassung von „Kernräumen“ gefordert (1981). Bei „speziellen Teilerscheinungen“ wie Klima, Vegetation und Böden ist dies mehr oder weniger zufriedenstellend gelungen. Ob das jemals auch für Formengemeinschaften unterschiedlicher Komplexität und unterschiedlichen Alters im Sinne einer „Klima-Geomorphologie“ möglich sein wird, oder ob das überhaupt erstrebenswert ist, darf bezweifelt werden, denn in den Abtragungsformen summiert sich immer die Gesamtheit aller Effekte der jeweiligen Klimageschichte (siehe A. PENCK 1905). Daher kann z.B. die augenfällige Zweiteilung unserer Mittelgebirge in Altflächen und jüngere, aber weitgehend fossile Täler nicht einfach mit Prozessen beschrieben werden, die in anderen „klima-morphologischen Zonen“ noch aktuell ablaufen sollen (vgl. BüDEL 1935 mit 1977, Fig. 13).

Es ist ein erklärtes Ziel des - von Julius BüDEL initiierten - Deutschen Arbeitskreises für Geomorphologie, auch „Neue Ansätze in der Erklärung der Reliefentwicklung in langen Zeitskalen (Geomorphogenetik)“ zu verfolgen (DiKAU 2006, S. V). 


\section{Literaturverzeichnis}

Ambrose J.W. (1964), Exhumed paleoplains of the Precambrian shield of North America. In: American Journal of Science, 262, S. 817-857.

Andersson J.G. (1906), Solifluction, a component of subaerial denudation. In: Journal of Geology, 14, S. 91-112.

Arbeitsgruppe Bodenkunde (1982³), Bodenkundliche Kartieranleitung. Stuttgart (1. Aufl. 1965 und 5. Aufl. 2005).

Aubert G. (1964), La classification des sols utilisée par les pédologues francais en zone tropicale ou aride. In: Sols Africains, IX, S. 97-105.

Aubert G. (1965), Classification des sols. In: Cahiers ORSTOM, série Pédologie, 3, S. 269-288.

B AILly F. et al. (2000), Synsedimentäre Paläo-Vertisole im Oberjura des westlichen Wiehengebirges. In: Osnabrücker Naturwiss. Mitt., 26, S. 15-46.

BECK N. (1994), Reliefentwicklung im nördlichen Rheinhessen unter besonderer Berücksichtigung der periglazialen Glacis- und Pedimentbildung. In: Forschungen z. dt. Landeskunde, 237, S. 1-175.

Becker G.F. (1895), Gold fields of the Southern Appalachians. In: $16^{\text {th }}$ Annual Report US Geological Survey, Part III. - Mineral Resources of the United States, 1894 Metallic Products, S. 251-331.

Beinroth F.H. (1965), Zur Kenntnis des Gilgai-Reliefs. In: Zeitschrift f. Pflanzenernährung, Düngung und Bodenkunde, 111, S. 221-227.

BiBus E. (1983), Die klimamorphologische Bedeutung von stone-lines und Decksedimenten in mehrgliederigen Bodenprofilen Brasiliens. In: Zeitschrift f. Geomorphologie N.F., Suppl.-Bd., 48, S. 79-98.

Bibus E., Nagel G., Semmel A. (1976), Periglaziale Reliefformung im zentralen Spitzbergen. In: Catena, 3, S. 29-44.

BLÜMel W.D. (1993), Contributions to Polar Geomorphology by the German Spitsbergen Expeditions 1990-1992. In: Zeitschrift f. Geomorphologie N.F., Suppl.-Bd., 92, S. 1-19.

BLÜMEL W.D. (Hrsg.) (1994), Geowissenschaftliche Spitzbergen-Expedition 1990-1992 (SPE 90-92) - Liefde-, Wood- und Bockford/NW-Spitzbergen. In: Zeitschrift f. Geomorphologie N.F., Suppl.-Bd., 97, S. 1-274.

Boquier G. et al. (1977), Géochimie de la surface et formes du relief. II. Interprétation pédologique des dépression annulaires entourant certains Inselbergs. In: Sciences Géologiques Bull., 30, S. 245-253.

Bork H.-R. et al. (1998), Landschaftsentwicklung in Mitteleuropa. Wirkungen des Menschen auf Landschaften. Gotha - Stuttgart, Klett-Perthes.

Bradley W.H. (1940), Pediments and Pedestals in Miniature. In: Journal of Geomorphology, 3 , S. 244-254.

Bray M.T., French H.M., Shur Y. (2006), Further Cryostratigraphic Observations in the CRREL Permafrost Tunnel, Fox, Alaska. In: Permafrost and Periglacial Processes, 17, S. 233-243.

Bremer H. (1984), Twenty-one years of German Geomorphology. In: Earth Surface Processes and Landforms, 9, S. 281-287.

Bremer H. (1989), Geomorphology in Germany (The Federal Republic of). In: Transactions of the Japanese Geomorphological Union, 10-B, S. 89-98.

Bremer H. (1993), Etchplanation, Review and Comments of Büdel's Model. In: Zeitschrift f. Geomorphologie N.F., Suppl.-Bd., 92, S. 189-200.

Bremer H. (1994), Soils in tropical geomorphology. In: Zeitschrift f. Geomorphologie N.F., 38 , S. 257-265. 
Bremer H. (2003), Morphogenese im Dekkan. In: Relief, Boden, Paläoklima, 18, S. 279-511. BREMER H. (2004), Climato-genetic geomorphology. In: Goudie A.S. (Hrsg.), Encyclopedia of Geomorphology, Vol. 1, S. 164-165. London - New York, Routledge.

Bremer H. (2004a), Relief generation. In: Goudie A.S. (Hrsg.), Encyclopedia of Geomorphology, Vol. 2, S. 842-843. London - New York, Routledge.

BRonger A. (1985), Bodengeographische Überlegungen zum „Mechanismus der doppelten Einebnung“ in Rumpfflächengebieten Südindiens. In: Zeitschrift f. Geomorphologie N.F., Suppl.-Bd., 56, S. 39-53.

BRÜCKNER H., BRUHN N. (1992), Aspects of weathering and peneplanation in southern India. In: Zeitschrift f. Geomorphologie N.F., Suppl.-Bd., 91, S. 43-66.

BRUnNer H. (1968), Geomorphologische Karten des Mysore-Plateaus (Süd-Indien) - ein Beitrag zur Methodik der morphologischen Kartierung in den Tropen. In: Wiss. Veröff. des Dt. Inst. f. Länderkunde N.F., 25/26, S. 5-17.

BRunNer H. (1968a), Geomorphologische Studien im Bereich des Mysore-Plateaus (Südindien) ein Beitrag zur Geomorphologie der Tropen. Habil.-Schrift, Hist.-phil. Fak. PH Potsdam.

BRUNNER H. (1969), Verwitterungstypen auf Granitgneisen (Peninsular Gneis) des östlichen Mysore-Plateaus (Südindien). In: PGM, 113, S. 241-248.

BRunNer H. (1970), Pleistozäne Klimaschwankungen im Bereich des Mysore-Plateaus (Südindien). In: Geologie, 19, S. 72-82.

BRUnOtTE E., GARLEFF K. (1989), Structural landforms and planation surfaces in southern Lower Saxony. In: Catena Supplement, 15, S. 151-164.

Buch M.W., Heine K. (1988), Klima- oder Prozeß-Geomorphologie. Gibt das jungquartäre fluviale Geschehen der Donau eine Antwort? In: Geogr. Rundschau, 40, S. 16-26.

BüDEL J. (1935), Die Rumpftreppe des westlichen Erzgebirges. In: Verhandlungen und Wissenschaftliche Abhandlungen des Deutschen Geographentags. Bad Nauheim 22. bis 24. Mai 1934, S. 138-147.

Büdel J. (1936), Zur Morphologie des Wiener Beckens. (Antwort auf Franz X. Schaffers Aufsatz: Mitt. d. Geogr. Ges. Wien, Bd. 78, 1935, S. 195ff.). In: Mitt. d. Geogr. Ges. Wien, 79, S. 28-31.

BÜDEL J. (1944), Die morphologischen Wirkungen des Eiszeitklimas im gletscherfreien Gebiet (Beiträge zur Geomorphologie der Klimazonen und Vorzeitklimate I). In: Geol. Rundschau, 34, S. 482-519.

Büdel J. (1950), Das System der klimatischen Morphologie. Beiträge zur Geomorphologie der Klimazonen und Vorzeitklimate (V). In: Deutscher Geographentag München 1948 S. $65-100$.

BüDEL J. (1954), Klima-morphologische Arbeiten in Äthiopien im Frühjahr 1953 (Beiträge zur Geomorphologie der Klimazonen und Vorzeitklimate X). In: Erdkunde, VIII, S. 139-156.

BüDEL J. (1957), Die „Doppelten Einebnungsflächen“ in den feuchten Tropen. In: Zeitschrift f. Geomorphologie N.F., 1, S. 201-228.

BüdEL J. (1957a), Grundzüge der klimamorphologischen Entwicklung Frankens. In: Würzburger Geogr. Arbeiten, 4/5, S. 5-46.

Büdel J. (1958), Die Flächenbildung in den feuchten Tropen und die Rolle fossiler solcher Flächen in anderen Klimazonen. In: Büdel J., Mensching H. (Hrsg.), Deutscher Geographentag, Würzburg 29. Juli bis 5. August 1957, Tagungsbericht und wissenschaftliche Abhandlungen, S. 89-109. Wiesbaden, Steiner.

Büdel J. (1960), Die Frostschutt-Zone Südost-Spitzbergens. In: Colloquium Geographicum, 6, S. 1-105.

BüDEL J. (1962), Die Abtragungsvorgänge auf Spitzbergen im Umkreis der Barentsinsel auf Grund der Stauferland-Expedition 1959/60. In: HartKe W., Wilhelm F. (Hrsg.), Deut- 
scher Geographentag, Köln 22. bis 26. Mai 1961, Tagungsbericht und wissenschaftliche Abhandlungen, S. 337-375. Wiesbaden, Steiner.

BüDEL J. (1962a), „Die beiden interstadialen Würmböden in Südbayern“. Eine Richtigstellung zu dem gleichnamigen Aufsatz von Ernst C. Kraus in diesem Jahrbuch 12, S. 43-58. In: Eiszeitalter und Gegenwart, 13, S. 178-180.

BüdEL J. (1963), Klima-genetische Geomorphologie. In: Geogr. Rundschau, 15, S. 269-286.

BüDEL J. (1965), Die Relieftypen der Flächenspülzone Süd-Indiens am Ostabfall Dekans gegen Madras. In: Colloquium Geographicum, 8, S. 1-100.

BüDEl J. (1966), Die Einflüsse des Grundwassers auf die Reliefbildung im semi-ariden SüdIndien. In: Nova Acta Leopoldina, 31 (Nr. 176), S. 107-129.

Büdel J. (1968), Hang- und Talbildung in Südost-Spitzbergen (auf Grund der StauferlandExpedition 1959 bis 1967). In: Eiszeitalter und Gegenwart, 19, S. 240-243.

BüDEL J. (1969), Der Eisrinden-Effekt als Motor der Tiefenerosion in der exzessiven Talbildungszone. In: Würzburger Geogr. Arbeiten, 25, S. 1-41.

Büdel J. (1970), Das geomorphologische Problem der Hangentwicklung. In: Würzburger Geogr. Arbeiten, 31 (= Vorwort zu Diss. Gossmann 1970), S. 1-5.

BüdEl J. (1970a), Der Begriff „Tal““. In: Tübinger Geogr. Studien, 34, S. 21-32.

BÜDEL J. (1970b), Pedimente, Rumpfflächen und Rückland-Steilhänge, deren aktive und passive Rückverlegung in verschiedenen Klimaten. In: Zeitschrift f. Geomorphologie N.F., 14, S. $1-57$.

BÜDEL J. (1971), Das natürliche System der Geomorphologie mit kritischen Gängen zum Formenschatz in den Tropen. In: Würzburger Geogr. Arbeiten, 34, S. 1-152.

Büdel J. (1971a), Aufriß des natürlichen Systems der Geomorphologie. Den Teilnehmern des 38. Deutschen Geographentags in Erlangen-Nürnberg überreicht von der Geographischen Gesellschaft Würzburg. In: Würzburger Geogr. Arbeiten, Sonderheft 34a, S. 1-78.

Büdel J. (1972), Geomorphologische Polarforschung in Spitzbergen. Kurzbericht der Ergebnisse der Stauferland-Expedition 1959-1967. In: Zeitschrift f. Gletscherkunde u. Glazialgeologie, 8, S. 283-294.

BüDEL J. (1972a), Typen der Talbildung in verschiedenen klimamorphologischen Zonen. In: Zeitschrift f. Geomorphologie N.F., Suppl.-Bd., 14, S. 1-20.

BüDEL J. (1974), Spitzbergen als Beispiel eiszeitlicher Reliefbildung in Mitteleuropa. In: Jahrbuch d. Bayer. Akad. d. Wiss. 1974, S. 1-20.

BüDEl J. (1975), Die Stellung der Geomorphologie im System der Naturwissenschaften. In: Zeitschrift f. Geomorphologie N.F., Suppl.-Bd., 23, S. 1-11.

BüdEL J. (1977), Klima-Geomorphologie. Berlin - Stuttgart, Gebr. Borntraeger (2. Aufl. 1981).

Büdel J. (1978), Geomorphologische Fragen des Früh-Pleistozän. In: NAGL H. (Hrsg.), Beiträge zur Quartär- und Landschaftsforschung. Festschrift zum 60. Geburtstag von Julius Fink, S. 53-63. Wien, Hirt.

BüDEL J. (1980), Climatic and Climatomorphic Geomorphology. In: Zeitschrift f. Geomorphologie N.F., Suppl.-Bd., 36, S. 1-8.

BüDEL J. (1981), Die Geographie lebt von der Grenze und leidet an ihr. Eine Lanze für die Landeskunde. In: Kisнiмото H. (Hrsg.), Geographie und ihre Grenzen (Boesch-Gedächtnisschrift), S. 39-43. Bern, Kümmerly \& Frey.

BüDEL J. (1981a), Die großen Prozeßgefüge und die Haupttypen subaerischer Reliefbildung. In: Zeitschrift f. Geomorphologie N.F., Suppl.-Bd., 39, S. 51-57.

BüDEL J. (1982), Climatic Geomorphology. Translated by Leonore Fischer and Detlef Busche. Princeton, N.J., Princeton Univ. Press.

Büdel J. (1986), Tropische Relieftypen Süd-Indiens (aus dem Nachlaß bearbeitet und herausgegeben von Detlef Busche). In: Relief, Boden, Paläoklima, 4, S. 1-84. 
BüDEL J. (1987), Die Abtragungsvorgänge in der exzessiven Talbildungszone Südost-Spitzbergens. In: Büdel J., Wirthmann A. (Hrsg.), Ergebnisse der Stauferland-Expedition. Deutsche Expeditionen nach Südost-Spitzbergen 1959/60 und 1967, Heft 1, S. 7-123.

Busche D., Kempf J., Stengel I. (2005), Landschaftsformen der Erde. Bildatlas der Geomorphologie. Darmstadt, Wiss. Buchges.

Butler B.E. (1959), Periodic Phenomena in Landscapes as a Basis for Soil Studies. In: C.S.I.R.O. Australian Soil Publ., 14, S. 1-20.

Butt C.R.M., ZeEgers H. (1992), Climate, geomorphological environment and geo-chemical dispersion models. In: Butt C.R.M., Zeegers H. (Hrsg.), Handbook of Exploration Geochemistry, Vol. 4, Regolith Exploration Geochemistry in Tropical and Subtropical Terrains, S. 3-24. Amsterdam et al., Elsevier.

Clayton R.W. (1956), Linear depressions (Bergfussniederungen) in savannah landscapes. In: Geographical Studies, III, S. 102-126.

C.C.T.A. - Commission de Coopération Technique en Afrique (1964), Carte des sols d'Afrique. Lagos.

CPCS - Commission de Pédologie et de Cartographie des Sols (1967), Classification des sols. - ENSA - Ecole Nationale Superieure Agronomique, Grignon.

Costin A.B. (1955), A note on Gilgaies and frost soils. In: Journal of Soil Science, 6, S. 32-34.

Credner W. (1932), Das Kräfteverhältnis morphogenetischer Faktoren und ihr Ausdruck im Formenbild Südost-Asiens. In: Bull. of the Geological Society of China, 11, S. 13-34.

Davis W.M. (1899), The geographical cycle. In: Geographical Journal, 14, S. 481-504.

Dege W. (1941), Landformende Vorgänge im eisnahen Gebiet Spitzbergens. In: PGM, 87, S. 81-97 und 113-122.

De Geer G. (1910), XI ${ }^{\mathrm{e}}$ Congrès Géologique International. Guide de 1'excursion au Spitzberg. A geological excursion to Central Spitzbergen. Stockholm, A.G. Nathorst und Söner.

D‘Hoore J. (1964), Projet conjoint No 11. La carte des sols d`Afrique au 1/5.000.000. In: Sols Africains, IX, S. 39-46.

Dikau R. (2006), Vorwort. In: Deutscher Arbeitskreis Für Geomorphologie (Hrsg.), Die Erdoberfläche - Lebens- und Gestaltungsraum des Menschen. Forschungsstrategische und programmatische Leitlinien zukünftiger geomorphologischer Forschung und Lehre (= Zeitschrift f. Geomorphologie N.F., Suppl.-Vol., 148, S. V-VI).

Douchaufour Ph. (1976), Atlas écologique des sols du monde. Paris et al., Masson.

Dregne H.E. (1976), Soils of Arid Regions (= Developments in Soil Science, 6). Amsterdam et al., Elsevier.

Eberle J., BlüMEL W.D. (1994), Die Kartierung der Bodengesellschaften auf der GermaniaHalbinsel (Liefdefjord/Spitzbergen) - Vorgehensweise, Abgrenzungskriterien und Bodensystematik. In: Zeitschrift f. Geomorphologie N.F., Suppl.-Bd., 97, S. 227-231.

Edelman C.H., Brinkman R. (1962), Physiography of gilgai soils. In: Soil Sciences, 94, S. 366-370.

Erhart H. (1956), La Genèse des Sols en tant que Phénomène Géologique. Esquisse d'une Théorie Géologique et Géochimique: Biostasie et Rhexistasie. In: Évolution des Sciences, 8, S. 1-90.

FAO-UNESCO (1974), Soil map of the world 1:5 000 000. Volume I: Legend. Paris.

Felix-Henningsen P. (1990), Die mesozoisch-tertiäre Verwitterungsdecke (MTV) im Rheinischen Schiefergebirge. Aufbau, Genese und quartäre Überprägung. In: Relief, Boden, Paläoklima, 6, S. 1-192.

FINCK A. (1963), Tropische Böden. Einführung in die bodenkundlichen Grundlagen tropischer und subtropischer Landwirtschaft. Hamburg - Berlin, Parey.

FLIEGEL G. (1913), Über tiefgründige chemische Verwitterung und subaerische Abtragung. In: Zeitschrift d. Dt. Geol. Ges., 65, S. 387-404. 
FöLSTER H. (1960), Über Entstehung und Dynamik indischer Regurböden, in Verbindung mit kritischen Untersuchungen zur Ordnung und Diagnostik der Tonminerale. Diss., Lw. Fak., Univ. Göttingen.

FöLSTER H. (1964), Morphogenese der südsudanesischen Pediplane. In: Zeitschrift f. Geomorphologie N.F., 8, S. 393-423.

FölSter H., LADEINDE T.A.O. (1967), The influence of stratification and age of pedisediments on clay distribution in ferruginous tropical soils. In: Pedologie, XVII, S. 212-231.

FräNZLE O. (1968), Valley evolution. In: FAIRBRIDGE R.W. (Hrsg.), The Encyclopedia of Geomorphology. Encyclopedia of Earth Sciences Series, Vol. III, S. 1183-1189. New York et al., Reinhold Book Cooperation.

FRÄNZLE O. (1976), Ein morphodynamisches Grundmodell der Savannen- und Regenwaldgebiete. In: Zeitschrift f. Geomorphologie N.F., Suppl.-Bd., 24, S. 177-184.

FRÄNZLE O. (1977), Hang- und Flächenbildung in den Tropen unter dem Einfluß der Eisen- und Aluminiumdynamik. In: Zeitschrift f. Geomorphologie N.F., Suppl.-Bd., 28, S. 62-80.

Gossmann H. (1970), Theorien zur Hangentwicklung in verschiedenen Klimazonen. Mathematische Hangmodelle und ihre Beziehung zu den Abtragungsvorgängen. In: Würzburger Geogr. Arbeiten, 31, S. 5-146.

Goudie A.S. (2004), Climatic geomorphology. In: Goudie A.S. (Hrsg.), Encyclopedia of Geomorphology, Vol. 1, S. 162-164. London - New York, Routledge.

Graul H. (1963), Konsequenzen aus J. Büdels Hypothese von der sarmato-pontischen Spülfläche in Süddeutschland. In: Berichte z. dt. Landeskunde, 31, S. 33-49.

Hagedorn H. (1984), Julius Büdel 8.8.1903 - 28.8.1983. In: Eiszeitalter und Gegenwart, 34, S. 219-221.

HARRIS S.A. (1981), Distribution of zonal permafrost landforms with freezing and thawing indices. In: Erdkunde, 36, S. 81-90.

НӧGвом В. (1912), Wüstenerscheinungen auf Spitzbergen. In: Bull. of the Geological Institute of the University of Uppsala, XI, S. 242-251.

НӧGвом В. (1913/14), Über die geologische Bedeutung des Frostes. In: Bull. of the Geological Institute of the University of Uppsala, XII, S. 257-390.

Holmsen G. (1914), Spitsbergens jordbundsis og de bidrag dens undersokelse har kunnet gi til forstaaelsen av de i arktiske land optraende varige isleier i jorden. In: Det Norske Geografiske Selskaps Aarbok, XXIV, S. 1-132.

Holmsen G. (1914a), Das Bodeneis Spitzbergens und die Beiträge, die seine Untersuchungen zum Verständnis der in arktischen Ländern auftretenden Eislagen in der Erde hat liefern können. In: Det Norske Geografiske Selskaps Aarbok, XXIV, S. 133-150.

Humlum O., Instanes A., Sollid J.L. (2003), Permafrost in Svalbard: a review of research history, climatic background and engineering challenges. In: Polar Research, 22, S. 191-215.

Karte J. (1981), Zur Rekonstruktion des weichselhochglazialen Dauerfrostbodens im westlichen Mitteleuropa. In: Bochumer Geogr. Arbeiten, 40, S. 59-71.

Kehl M., Murti R.N., Skowronek A. (2007), Zur polygenetischen Bodenbildung in einem Inselberg-Pediment-Pediplainrelief bei Kolar/Südindien. In: Bonner Bodenkundl. Abhandlungen, 46, S. 127-151.

Kiewietdejonge C.J. (1984), Büdel's geomorphology I and II. In: Progress in Physical Geography, 8, S. 218-248 und 365-397.

King L.C. (1953), Canons of landscape evolution. In: Geological Society of America Bull., 64, S. 721-751.

KING L. (1957), The Uniformitarian Nature of Hillslopes. In: Transactions of the Edinburgh Geological Society, 17, S. 81-102.

KÖRBER H. (1962), Die Entwicklung des Maintals. In: Würzburger Geogr. Arbeiten, 10, S. 1-170. 
Kraus E. (1922), Der Blutlehm auf der süddeutschen Niederterrasse als Rest des postglazialen Klimaoptimums. In: Geognostisches Jahresheft, 34, S. 169-222.

Kraus E. (1923), Die Bodenkunde als Methode in der Morphologie. In: PGM, 69, S. 1-6.

Krebs N. (1929), Ebenheiten und Inselberge im Karst. In: Zeitschrift d. Ges. f. Erdkunde zu Berlin, 3/4, S. 81-94.

Krebs N. (1933), Morphologische Beobachtungen in Südindien. In: Sitzungsberichte d. Preuß. Akad. d. Wiss., Phys.-Math. K1. XXIII, S. 692-721.

Krebs N. (1936), Klima und Bodenbildung in Südindien. In: Zeitschrift d. Ges. f. Erdkunde zu Berlin, 3-4, S. 87-101.

KreBs N. (1942), Über Wesen und Verbreitung der tropischen Inselberge. In: Abhandlungen d. Preuß. Akad. d. Wiss., Math.-Naturwiss. K1., Nr. 6, S.1-41.

Lachenbruch A.H. (1962), Mechanics of Thermal Contraction Cracks and Ice-Wedge Polygons in Permafrost. In: Geological Society of America Special Paper, 70, S. 1-69.

Laufenberg M. (2003), Tropische Verwitterung und Bodenbildung in basaltischen und kristallinen Gesteinen Indiens. In: Relief, Boden, Paläoklima, 18, S. 1-277.

Lecomte P. (1988), Stone line profiles: Importance in geochemical exploration. In: Journal of Geochemical Exploration, 30, S. 35-61.

Leffingwell E. DE K. (1915), Ground-ice wedges. The dominant form of ground-ice on the north coast of Alaska. In: Journal of Geology, 23, S. 635-654.

Leffingwell E. De K. (1919), The Canning River region, northern Alaska. In: United States Geological Survey Professional Paper, 109, S. 1-251.

Lehmann H. (1953), Karst-Entwicklung in den Tropen. In: Umschau, 53 (18), S. 559-562.

Lehmann H. (1964), Glanz und Elend der morphologischen Terminologie. Festvortrag anlässlich des 60. Geburtstages von Prof. Dr. J. Büdel. In: Würzburger Geogr. Arbeiten, 12, S. 11-22.

Louis H. (1983), Julius Büdel, eine Würdigung. In: Geoökodynamik, 4, S. 145-148.

Louis H. (1986), Zur geomorphologischen Unterscheidung zwischen Talbildung und Flächenbildung. In: Zeitschrift f. Geomorphologie N.F., 30, S. 275-290.

LozINSKI W. (1909), Über die mechanische Verwitterung der Sandsteine im gemäßigten Klima. In: Bull. International de 1'Academie de Sciences de Cracovie, Cl. des Sci. math. et nat., $\mathrm{N}^{\circ} 1, \mathrm{~S} .1-25$.

Mаввuтt J.A. (1961), , Basal Surface‘ or , Weathering front‘. In: Proc. of the Geological Association London, 72, S. 357-358.

MackaY J.R. (1972), The World of Underground Ice. In: Annals of the Association of American Geographers, 62, S. 1-22.

Maignien R. (1965), Notice explicative - Carte pédologique du Senegal au 1/1 000000 . ORStOM - Office de la Recherche Scientifique et Technique Outre-Mer, Paris, Selbstverlag.

Mensching H. (1951), Akkumulation und Erosion niedersächsischer Flüsse seit der Rißeiszeit. In: Erdkunde, 5, S. 60-70.

Mensching H. (1984), Julius Büdel und sein Konzept der Klima-Geomorphologie - Rückschau und Würdigung. In: Erdkunde, 38, S. 157-166.

Meyer B. (1979), Die Entcarbonatierungsrötung als bodengenetischer Teilprozeß. In: Mitt. d. Dt. Bodenkundl. Ges., 29, S. 705-708.

Meyer R. (1966), Über Flächenbildung in den wechselfeuchten Tropen. Kritische Gedanken zu den Vorstellungen von J. Büdel. In: Mitt. d. Geogr. Ges. München, 51, S. 183-204.

Migon P. (2006), Büdel, J. 1982: Climatic geomorphology. Princeton: Princeton University Press. (Translation of Klimageomorphologie, Berlin-Stuttgart: Gebrüder Borntraeger, 1977) In: Progress in Physical Geography, 30, S. 99-103. 
Miotкe F.-D. (1979), Permafrosthänge im Yukon Tanana-Upland, Alaska. In: Trierer Geogr. Studien, Sonderh. 2, S. 112-140.

Mortensen H. (1954/55), Die „quasinatürliche“ Oberflächenformung als Forschungsproblem. In: Wiss. Zeitschrift d. Ernst-Moritz-Arndt-Univ. Greifswald, IV, Math.-Naturwiss. Reihe Nr. 6/7, S. 625-628.

Mortensen H. (1963), Abtragung und Formung. In: Nachrichten d. Akad. d. Wiss. in Göttingen aus dem Jahre 1963, Math.-Phys. K1., S. 17-27.

Passarge S. (1930), Der geographische Wert des Bodens (Boden und Kulturentwicklung). In: Blanck E. (Hrsg.), Handbuch der Bodenlehre V, Der Boden als oberste Schicht der Erdoberfläche, S. 429-454. Berlin, Springer.

Penck A. (1905), Climatic Features in the Land Surface. In: American Journal of Science, $4^{\text {th }}$ Ser., 19 , S. 165-174.

Penck W. (1924), Die morphologische Analyse. Ein Kapitel der physikalischen Geologie. In: Geogr. Abhandlungen, 2. Reihe, Heft 2, S. 1-283.

Pias J., Poisot P. (1964), Notice explicative - Cartes pédologiques de reconnaissance au 1/200.000. Feuilles de Bokoro-Guéra-Mongo. ORSTOM - Office de LA Recherche Scientifique ET Technique Outre-Mer, Paris, Selbstverlag.

Priesnitz K. (1988), Cryoplanation. In: Clark M.J. (Hrsg.), Advances in Periglacial Geomorphology, S. 49-67. London, John Wiley \& Sons Ltd.

Ramann E. (1918), Bodenbildung und Bodeneinteilung (System der Böden). Berlin, Julius Springer.

Ramann E. (1918/19), Der Boden und sein geographischer Wert. In: Mitt. d. Geogr. Ges. München, XIII, S. 1-14.

RAPP A. (1957), Studien über Schutthalden in Lappland und auf Spitzbergen. In: Zeitschrift f. Geomorphologie N.F., 1, S. 179-200.

Rathuens C. (1971), Einleitung: Grundzüge der Klimatischen Geomorphologie. In: Rathuens C. (Hrsg.), Klimatische Geomorphologie, S. 1-29. Darmstadt, Wiss. Buchges.

Rathuens C. (Hrsg.) (1971a), Klimatische Geomorphologie (= Wege der Forschung, Bd. CCXVIII). Darmstadt, Wiss. Buchges.

Reinwarth O., StäBlein G. (1972), Die Kryosphäre - das Eis der Erde und seine Untersuchung. In: Würzburger Geogr. Arbeiten, 36, S. 1-71

RoHDENBURG H. (1966), Eiskeilhorizonte in südniedersächsischen und nordhessischen Lössprofilen. In: Mitt. d. Dt. Bodenkundl. Ges., 5, S. 137-170.

Rohdenburg H. (1968), Zur Deutung der quartären Taleintiefung in Mitteleuropa. In: Die Erde, 99, S. 297-304.

Rohdenburg H. (1969), Hangpedimentation und Klimawechsel als wichtigste Faktoren der Flächen- und Stufenbildung in den wechselfeuchten Tropen an Beispielen aus Westafrika, besonders aus dem Schichtstufenland Südost-Nigerias. In: Giessener Geogr. Schriften, 20, S. 57-152 und in: Göttinger Bodenkundl. Berichte, 10, S. 57-152.

Rohdenburg H. (1970), Hangpedimentation und Klimawechsel als wichtigste Faktoren der Flächen- und Stufenbildung in den wechselfeuchten Tropen. In: Zeitschrift f. Geomorphologie N.F., 14, S. 58-78.

Rohdenburg H. (1970a), Morphodynamische Aktivitäts- und Stabilitätszeiten statt Pluvial- und Interpluvialzeiten. In: Eiszeitalter u. Gegenwart, 21, S. 81-96.

Rohdenburg H. $\left(1971^{2}\right)$, Einführung in die klimagenetische Geomorphologie anhand eines Systems von Modellvorstellungen am Beispiel des fluvialen Abtragungsreliefs. Gießen, Lenz-Verlag (1. Aufl. 1971, 3. Aufl. 2006).

Rohdenburg H. (1989), Landschaftsökologie - Geomorphologie [Aus d. Ms. bearb. u. hrsg. von Margot Rohdenburg]. Cremlingen-Destedt, Catena. 
Rohdenburg H., Meyer B. (1963), Rezente Mikroformung in Kalkgebieten durch inneren Abtrag und die Rolle der periglazialen Gesteinsverwitterung. Eine geomorphologische Auswertung von Bilanzanalysen an Bodenprofilen. In: Zeitschrift f. Geomorph. N.F., 7, S. 120-146.

Rohdenburg H., SAbelberg U., W agner H. (1976), Sind konkave und konvexe Hänge prozessspezifische Formen? Ergebnisse von Hangentwicklungssimulationen mittels EDV. In: Catena, 3, S. 113-136.

RuHE R.V. (1975), Climatic geomorphology and fully developed slopes. In: Catena, 2, S. 309-320.

Russell I.C. (1890), Notes on the Surface Geology of Alaska. In: Geological Society of America Bull., 1, S. 99-162.

RUXTON B.P., BERRY L. (1961), Weathering profiles and geomorphic position on granite in two tropical regions. In: Revue de Géomorphologie Dynamique, 12, S. 16-31.

SALOMON W. (1910), Die Spitzbergenfahrt des Internationalen Geologischen Kongresses. In: Geol. Rundschau, 1, S. 302-309.

Salomon W. (1917), Die Bedeutung der Solifluktion für die Erklärung deutscher Landschaftsund Bodenformen. In: Geol. Rundschau, 7, S. 30-41.

SAlomon W. (1929), Arktische Bodenformen in den Alpen. In: Sitzungsber. d. Heidelberger Akad. d. Wiss., Math.-Naturwiss. K1., Abh. 5, S. 1-31.

SchefFer F., FöLSTER H., MeYer B. (1959/60), Zur Entstehung von Schwarzerden und schwarzerdeartigen Böden. I. Mitteilung: Der indische Regur als Beispiel für tropische Schwarzerdebildung. In: Chemie der Erde, 20, S. 302-330.

Schenk E. (1955), Die Mechanik der periglazialen Strukturböden. In: Abhandlungen d. hessischen Landesamtes f. Bodenforschung, 13, S. 1-92.

Schmidt-Lorenz R. (1971), Die Böden der Tropen und Subtropen. In: Blanckenburg P. von, Cremer H.-D. (Hrsg.), Handbuch der Landwirtschaft und Ernährung in den Entwicklungsländern, Bd. 2, Pflanzliche und tierische Produktion in den Tropen und Subtropen, S. 44-80. Stuttgart, Eugen Ulmer.

Schmitthenner H. (1956), Probleme der Schichtstufenlandschaft. In: Marburger Geogr. Schriften, 3, S. 1-87.

SCHRÖDER B. (1970), Fränkische Schweiz und Vorland (= Sammlung Geologischer Führer, Bd. 50; 3. Aufl. 1977). Berlin - Stuttgart, Gebr. Borntraeger.

SCHRÖDER B. (1996), Zur känozoischen Morphotektonik des Stufenlandes auf der Süddeutschen Großscholle. In: Zeitschrift f. geol. Wissenschaften, 24, S. 55-64.

Schumm S.A. (1962), Erosion on Miniature Pediments in Badlands National Monument, South Dakota. In: Geological Society of America Bull., 73, S. 719-724.

Schwarzbach M. (1968), Das Klima des rheinischen Tertiärs. In: Zeitschrift d. Dt. Geol. Ges., 118, S. 33-68

Semmel A. (1985), Periglazialmorphologie (= Erträge d. Forschung, 231). Darmstadt, Wiss. Buchges

Semmel A. (1989), The importance of loess in the interpretation of geomorphological processes and for dating in the Federal Republic of Germany. In: Catena Supplement, 15, S. 179-188.

Semmel A. (1993), Das aktualistische Prinzip und seine Anwendung in der deutschen TropenGeomorphologie. In: Zeitschrift f. Geomorph. N.F., Suppl.-Bd., 93, S. 47-59.

Semmel A. (2008), Vorzeitliches Eiszeitklima und heutiger Boden im Spessart. In: Jahresberichte der Wetterauischen Ges. f. d. gesamte Naturkunde zu Hanau, 158, S. 97-117.

Seuffert O. (1973), Die Laterite am Westsaum Südindiens als Klimazeugen. In: Zeitschrift f. Geomorphologie N.F., Suppl.-Bd., 17, S. 242-259.

SeufFert O. (1986), Geoökodynamik - Geomorphodynamik. Aktuelle und vorzeitliche Formungsprozesse in Südindien und ihre Steuerung durch raum/zeitliche Variationen der geo-ökologischen Raumgliederung. In: Geoökodynamik, 7, S. 161-214. 
Seuffert O. (1988), Das aktuelle Formungsspektrum im semiariden Südindien und seine geoökologisch/anthropogenen Grundlagen. In: Hagedorn J., Mensching H. (Hrsg.), Aktuelle Morphodynamik und Morphogenese in den semiariden Randtropen und Subtropen, S. 181-212. Göttingen, Vandenhoeck \& Ruprecht.

Skowronek A. (1987), Böden als Indikator klimagesteuerter Landformung in der zentralen Sahara. In: Relief, Boden, Paläoklima, 5, S. 1-184.

Skowronek A., Murti R.N. (2005), Bodengenese und Bodenvergesellschaftung in einem Inselberg-Pediment-Pediplainrelief bei Kolar/Südindien. In: Mitt. d. Dt. Bodenkundl. Ges., 107, S. 407-408.

Sмітн J. (1956), Some moving soils in Spitzbergen. In: Journal of Soil Sciences, 7, S. 10-21.

Soll Survey Staff (1960), Soil classification - a comprehensive system. $7^{\text {th }}$ Approximation. Washington D.C., Selbstverlag.

Soll Survey Staff (1975), Soil Taxonomy. A Basic System of Soil Classification for Making and Interpreting Soil Surveys. In: Agriculture Handbook No. 436, S. 1-754. Washington D.C., Selbstverlag.

Sрӓтн H. (1986), Die Bedeutung der „Eisrinde“ für die periglaziale Denudation. In: Zeitschrift f. Geomorphologie N.F., Suppl.-Bd., 61, S. 3-23.

Späth H. (1995), Böden und Ablagerungen im Kristallin des Dekkans. In: Bremer H. et al. (Hrsg.), Boden und Relief in den Tropen: Grundvorstellungen und Datenbank. Relief, Boden Paläoklima, 11, S. 146-149.

StÄBleIN G. (1970), Untersuchung der Auftauschicht über Dauerfrost in Spitzbergen. In: Eiszeitalter u. Gegenwart, 21, S. 47-57.

StÄBlein G. (1972), Zur Frage geomorphologischer Spuren arider Klimaphasen im Oberrheingebiet. In: Zeitschrift f. Geomorph. N.F., Suppl.-Bd., 15, S. 66-86.

StÄBleIN G. (1977), Rezente Morphodynamik und Vorzeitreliefinfluenz bei der Hang- und Talentwicklung in Westgrönland. In: Zeitschrift f. Geomorphologie N.F., Suppl.-Bd., 28, S. 181-199.

StÄвlein G. (1984), Der klimagenetische Ansatz und Julius Büdel's Modell der Reliefgenerationen. In: Zeitschrift f. Geomorphologie N.F., Suppl.-Bd., 50, S. 137-152.

StäBlein G. (1984a), In memoriam Julius Büdel (1903-1983). In: Die Erde, 115, S. 177-182.

StÄBlein G. (1987), Die Bedeutung der Talbildung im Rahmen der Abtragungsvorgänge der Polaren Zonen - Zusammenfassung der Diskussion und neuere Ergebnisse. In: BüDEL J., Wirthmann A. (Hrsg.), Ergebnisse der Stauferland-Expedition. Deutsche Expeditionen nach Südost-Spitzbergen 1959/60 und 1967, Heft 1, S. 124-131. Wiesbaden, Franz Steiner.

Stengel I. (2002), Alte Verwitterung - junge Folgen: Reliefgenese in Südnamibia. In: PGM, 146, S. 16-23.

Stremme H. (1910), Überreste tertiärer Verwitterungsrinden in Deutschland. In: Geol. Rundschau, 1, S. 337-344.

Stremme H. (1917), Profile tropischer Böden. In: Geol. Rundschau, 8, S. 80-88.

TABER S. (1943), Perennially frozen ground in Alaska: its origin and history. In: Geological Society of America Bull., 54, S. 1433-1548.

Tedrow J.C.F. (1977), Soils of the polar landscapes. New Brunswick, Rutgers Univ. Press.

Thomas M.F. (1994), Geomorphology in the Tropics. A Study of Weathering and Denudation in Low Latitudes. Chichester et al., John Wiley \& Sons.

Thorbecke F. (Hrsg.) (1927), Düsseldorfer Geographische Vorträge und Erörterungen. In: Verhandlungen der geographischen Abteilung der 89. Tagung der Gesellschaft deutscher Naturforscher und Ärzte in Düsseldorf 20.-24. Sept. 1926. Dritter Teil: Morphologie der Klimazonen, S. 1-100. Breslau, Ferdinand Hirt. 
TILl A. (1932/33), Ortsbodentypen. In: Bodenkundl. Forschungen, III, S. 163-195.

Trendall A.F. (1962), The Formation of "Apparent Peneplains" by a process of combined lateritisation and surface wash. In: Zeitschrift f. Geomorphologie N.F., 6, S. 183-197.

Tricart J. (1951), Die Entstehungsbedingungen des Schichtstufenreliefs im Pariser Becken. In: PGM, 95, S. 98-104.

Tricart J. (1958), Büdel (J.), 1957 Die „Doppelten Einebnungsflächen“ in den feuchten Tropen. Zeitschr. für Geomorphologie, I, p. 201-228. In: Revue de Géomorphologie Dynamique, 9, S. 29.

Troll C. (1973), Julius Büdel und die moderne Geomorphologie. Eine Würdigung seines Werkes anläßlich seines 70. Geburtstages. In: Erdkunde, 27, S. 245-253.

Wahnschaffe F. (1910), Die Exkursion des XI. Internationalen Geologen-Kongresses nach Spitzbergen. In: Zeitschrift d. Ges. f. Erdkunde zu Berlin 1910, 10, S. 639-654.

W Andel G. (1950), mit Beitr. von MücKenhausen E., Neue vergleichende Untersuchungen über den Bodenabtrag an bewaldeten und unbewaldeten Hangflächen in Nordrheinland. In: Geol. Jahrbuch, 65, S. 507-550.

Weise O.R. (1983), Das Periglazial. Geomorphologie und Klima in gletscherfreien, kalten Regionen. Berlin - Stuttgart, Borntraeger.

WiLliams G.E. (1969), Characteristics and origin of a Precambrian pediment. In: Journal of Geology, 77, S. 183-207.

Williams P.J. (1966), Downslope soil movement at a subartic location with regard to variation. In: Canadian Geotechnical Journal, 3, S. 191-203.

Wirthmann A. (1976), Reliefgenerationen im unvergletscherten Polargebiet. In: Zeitschrift f. Geomorphologie N.F., 20, S. 391-404.

Wirthmann A. (1977), Erosive Hangentwicklung in verschiedenen Klimaten. In: Zeitschrift f. Geomorphologie N.F., Suppl.-Bd., 28, S. 42-61.

WiRthmann A. (1981), Täler, Hänge und Flächen in den Tropen. In: Geoökodynamik, 2, S. 165-203.

WiRTHMAnN A. et al. (1983), Nachruf auf Julius Büdel von seinen Schülern. In: Geoökodynamik, 4, S. 343-345.

Wirthmann A. (1987), Geomorphologie der Tropen (= Erträge der Forschung, Bd. 248) (2. Aufl. 1994). Darmstadt, Wiss. Buchges.

Wirthmann A. (1994), Gedanken zur Genese der Gäufläche oder die Grenzen der KlimaGeomorphologie. In: Würzburger Geogr. Arbeiten, 89, S. 65-71.

Wirthmann A. (2000), Geomorphology of the Tropics. Translated by Detlef Busche. Berlin Heidelberg, Springer.

Wissmann H. von (1954), Der Karst der humiden heißen und sommerheißen Gebiete Ostasiens. In: Erdkunde, 8, S. 122-130. 